\title{
El servicio público de televisión en el Reino Unido: cambio y europeización (1979-2010)
}

\author{
Esteban Arribas Reyes \\ Universidad de Alcalá \\ esteban.arribas@uah.es
}

\begin{abstract}
Resumen
A partir del reconocimiento del peso de la historia en la continuidad o estabilidad de las políticas públicas, el presente artículo analiza el cambio en las políticas gubernamentales del servicio público de televisión en sistemas políticos europeos. El análisis se centra en las políticas de servicio público de televisión que implementa la $B B C$. El caso del Reino Unido es relevante porque la $B B C$ es el paradigma de la independencia y autorregulación del servicio público de televisión en el mundo. Además, es un modelo que tradicionalmente ha servido como motor de cambio en las políticas de servicio público de televisión en el conjunto de los Estados miembros de la Unión Europea y también en la esfera global. La combinación novedosa de conceptos y teorías para el análisis del cambio en la fase de predecisión del proceso de elaboración de políticas públicas -definición del problema y formación de la agenda gubernamental-, junto con la introducción necesaria del enfoque de europeización de políticas públicas como desafío metodológico, nos permite completar las dinámicas del sistema político británico desde 1979 hasta el 2010. Se ha seleccionado este período de análisis porque en él se producen los cambios más profundos en el modelo de servicio público de televisión de la $B B C$, incluyendo aquellos que podrían derivar del proceso de integración europea.
\end{abstract}

\section{Public Broadcasting Service in the United Kingdom: Policy Change and Europeanization (1979-2010)}

\begin{abstract}
Considering the weight of history -i.e. policy continuity and stability- this article analyses change of public service broadcasting (PSB) policies in European political systems. This analysis focuses on PSB television policies implemented by the BBC. The United Kingdom's case is relevant because the BBC is a global paradigm of PSB independence and self-regulation and it has been traditionally a model and engine for PSB television policy change in both European Union Member States and the global sphere. An original combination of theories and concepts for change analysis within the predecision stage of the policy-making process -problem definition and agenda-setting processes-, along with the necessary introduction of the europeanization of public policy approach as a methodological challenge to the study of change, let us complete British political system dynamics from 1979 to 2010. This research period has been selected because the BBC public service broadcasting has experienced the deepest changes in history, including those where the European integration process could have had an impact.
\end{abstract}

Keywords

Public service broadcasting television, policy change, European integration dynamics, Europeanization, United Kingdom, British Broadcasting Corporation (BBC). 


\section{PREMISAS INTRODUCTORIAS}

La televisión es la fuente principal de información y entretenimiento en Europa. Los ciudadanos europeos emplean más de tres horas diarias de media cada uno viendo noticias, deportes, películas y otros programas. El sector audiovisual proporciona más de un millón de empleos en la Unión Europea (UE) y está inmerso en grandes intereses comerciales, así como en temas de gran relevancia para el desarrollo de las democracias como la diversidad cultural, el servicio público y la responsabilidad social'1.

El concepto de servicio público de televisión es inherente a la relación histórica entre mercado y Estado en Europa. La televisión en Europa fue tradicionalmente una actividad reservada al Estado. Desde su comienzo, fue ofrecida por operadores públicos -por ejemplo, British Broadcasting Corporation (BBC), Radio Televisión Española (RTVE), Radiotelevisione Italiana (RAI)- bajo un régimen de monopolio, principalmente como consecuencia de la disponibilidad limitada de las frecuencias para su emisión y las grandes barreras de acceso. En el período de entreguerras, los poderes públicos retuvieron tecnologías de información esenciales para el ejército, primero la radio y más tarde la televisión. Así nace en Europa el servicio público de televisión, bajo la titularidad del Estado.

Sin embargo, en los años setenta, los desarrollos tanto económicos como tecnológicos hicieron paulatinamente posible para los Estados europeos la entrada de otros operadores de televisión. Por lo tanto, los Estados decidieron introducir competencia en el mercado. Al tiempo que se abrían los mercados a la competencia, los gobiernos consideraron que el servicio público de televisión se debía mantener, como forma de asegurar la cobertura a numerosos lugares y la satisfacción de unas necesidades (garantía del derecho a la información y, por tanto, acceso en condiciones de universalidad e igualdad) que los operadores privados no realizarían necesariamente de una forma óptima².

1 El concepto de responsabilidad social de los medios de comunicación, aplicable a nuestro objeto de estudio -el servicio público de televisión- tiene su origen en la teoría de la responsabilidad social desarrollada por primera vez por Robert Maynar Hutchins en la Hutchins Commission on Freedom of the Press (1947). En la actualidad, sería interesante combinar esta teoría con la noción de responsabilidad social corporativa como herramienta de gestión de los medios de comunicación, sean estos públicos o privados, donde se engloban aspectos sociales, medioambientales y de gobernanza (política editorial y libertad de expresión, ética del profesional, publicidad responsable, obligación de educar e informar, transparencia, integridad y rendición de cuentas, protección del medio ambiente en su producción y contenidos, etc.). Consultar, por ejemplo, SustainAbility (2002).

2 El artículo comparte las recomendaciones del Consejo de Europa, en su Recomendación 1641 (2004) en su punto 1, donde dice: "El servicio público de televisión, un elemento vital para la democracia en Europa, está bajo amenaza. Es presionado tanto por poderes económicos como políticos, mediante el incremento de la competencia en los medios de comunicación, por la concentración de los medios de comunicación y por las dificultades financieras. Además, debe encarar el reto de la globalización y las nuevas tecnologías". En el punto 2 añade -y aquí estaría la clave de la diferenciación e importancia de los operadores públicos de televisión como objeto de este estudio, lo que, además, concuerda con la definición de esta investigación-: “El servicio público de televisión, independientemente de que lo gestione una organi- 
En ese escenario, las políticas de servicio público de televisión de los Estados miembros de la UE han sufrido importantes cambios en las dos últimas décadas. La desaparición de los monopolios, la aparición de nuevos operadores (competencia) y el rápido desarrollo tecnológico han alterado fundamentalmente la definición de los problemas y agendas gubernamentales, determinando la selección de las alternativas u opciones de políticas públicas. Estos procesos han producido cambios tanto en el ámbito doméstico o nacional, como de la UE.

Aunque la formulación de las políticas de servicio público de televisión y su implementación por organismos públicos sigue siendo una política que es competencia de los Estados miembros (Muñoz, 2007: 18-19), el escenario en la UE ha cambiado desde finales de los años noventa. La política audiovisual en ella, y en particular la del servicio público de televisión, muestra tensiones entre los diferentes tipos de objetivos o soluciones de políticas y enfoques que tienen los diferentes actores políticos: el enfoque social, el cultural y el político por un lado, y el económico por otro. Así, mientras la UE reconoce la importancia del servicio público de televisión como bien público (es decir, bienes y beneficios de y para el disfrute de la comunidad) que tiene potencial democrático, exige que la financiación del Estado para el servicio público de televisión no afecte a las condiciones de mercado y a la competencia en la UE hasta el punto que fuera contrario al interés común comunitario.

El artículo da importancia al servicio público de televisión en su relación con el desarrollo de las democracias ${ }^{3}$, utilizando los instrumentos que nos proporciona la ciencia política y, en particular, el análisis de políticas públicas. Este enfoque nos ayuda a obtener claves relevantes del funcionamiento de los sistemas políticos democráticos ${ }^{4}$. La relevancia del objeto de artículo no es baladí. La televisión es aún hoy el

zación pública o pertenezca a empresas privadas, difiere por su misión de la televisión por razones exclusivamente comerciales o políticas, la cual es, esencialmente, la de operar independientemente de aquellos que ostenten tanto poder económico como político. Proporciona a toda la sociedad información, cultura, educación y entretenimiento; promueve la ciudadanía social, política y cultural y promueve la cohesión social. Para ello, es universal en términos de contenido y acceso; proporciona un indicador de calidad; ofrece una variedad de programas y servicios que se adecua a las necesidades de todos los grupos de la sociedad y rinde cuentas públicamente. Estos principios aplican, cualquiera de los cambios que puedan introducirse para llegar a los requerimientos del siglo XXI".

3 La democracia funciona a través de procesos de comunicación libres que configuran la opinión pública y la ciudadanía. Una opinión pública bien informada es esencial para el buen funcionamiento de las democracias. Los medios de comunicación en general, pero principalmente la televisión, construyen la agenda de los temas que se consideran relevantes o importantes para la opinión pública. Así, MacCombs y Shaw (1972: 2) resaltan la importancia de los medios de comunicación como elementos esenciales de construcción de la agenda de las sociedades. Por otro lado, un entendimiento general de los sistemas políticos contemporáneos implica una buena comprensión del papel de los medios de comunicación de masas en general y de la televisión en particular (Dahlgren, 2000).

4 El enfoque de políticas públicas nos ayuda a conocer mejor la evolución y desarrollo de los sistemas políticos. Nos permite analizar la caja negra de sus dinámicas para comprender mejor su funcionamiento. En definitiva, es el estudio del Estado, el poder y sus dinámicas. El enfoque de análisis de políticas públicas nos permitirá analizar el proceso de elaboración de las políticas de los servicios públicos de televisión de Estados miembros de la UE. Este análisis nos acercará al conocimiento de las dinámicas de políticas públicas dentro del proceso de integración europeo. 
medio tecnológico más influyente para el desarrollo de las sociedades democráticas europeas 5 . Es decir, la televisión posee un tipo de poder singular dentro de las mismas. La influencia de las imágenes de la televisión altera los procesos de comunicación hasta el extremo de haber cambiado la apariencia del Homo Videns que nos describe Giovanni Sartori (2008), y se ha convertido en un elemento esencial para conocer las transformaciones de las sociedades democráticas a través del análisis de la esfera de lo público (Habermas, 2002). Además, es interesante la introducción del tema en España, donde no existe un debate político sustancial, no hay artículos politológicos relevantes, y menos desde el enfoque de políticas públicas.

La literatura de análisis de políticas públicas nos indica que las características de la mayoría de las políticas públicas son la continuidad o estabilidad, así como el cambio incremental (Meijerink, 2005: 1060) ${ }^{6}$. En este artículo nos interesa analizar cómo se podrían explicar períodos de cambio, a menudo drásticos, aunque también incrementales, lentos, parciales o marginales, teniendo en cuenta, además, el proceso de integración europea?.

El objetivo de la investigación es comprender el cambio en el paradigma ${ }^{8}$ de las políticas de servicio público de televisión en el Reino Unido y explicar las diferentes elecciones de políticas públicas mediante el control de hipótesis contrarias y alternativas, que se entienden en esta investigación como el resultado del proceso de formación de la agenda en sus diferentes corrientes de problemas, políticas y política (Kingdon, 1995), dentro del proceso de integración europea. Intentaremos entender las

5 Entre otros estudios, se puede consultar la encuesta anual The Deloitte State of Media Democra$c y$ (2009), donde se concluye que la televisión es aún hoy el medio de comunicación más influyente. Es el medio a través del cual se informan los ciudadanos, en un proceso esencial, aunque no determinante, de su participación en democracia. Sin embargo, hay que tener en cuenta para el futuro no muy lejano los nuevos medios de comunicación como Internet.

6 No es el objetivo de este artículo aplicar las teorías y conceptos que explican la continuidad o estabilidad de las políticas públicas por razones de espacio y concreción, aunque ello haya significado desechar el peso de la historia que, fundamentalmente, ha resultado en el mantenimiento de los principales principios y marcos regulatorios de una institución pública, la BBC, desde 1927. Para explicar períodos de estabilidad y continuidad, consultar, por ejemplo, los conceptos y teorías que nos proporciona el nuevo institucionalismo. En particular, el institucionalismo histórico (Pierson y Scokpol, 2002; Greener, 2005) y el concepto de "path dependence" o "dependencia del sendero" (Greener, 2005).

7 Además, en el caso de muchas de las políticas públicas de los Estados miembros de la UE se observa que los grupos de interés han aprendido a explotar las oportunidades que se han presentado en un proceso de elaboración de políticas públicas, caracterizado cada vez más por una estructura de oportunidades múltiple (Richardson, 2000: 1006).

8 El uso del término “paradigma” (Kuhn, 1970), en ciencias sociales, tiene diferentes significados. En este caso, utilizamos el término para describir las experiencias, creencias y valores que quizás influyan en la forma en que el individuo (policy-maker) percibe la realidad, y la forma en que él o ella responde a esa percepción. Existen varios trabajos que se refieren a paradigmas dentro de la literatura sobre políticas públicas. En esta investigación se han utilizado: Hall (1993), Jenson (1989), Capano (1999) y Sabatier (1999). Existen varios enfoques para estudiar los paradigmas. En este artículo se entiende que el enfoque que proporciona Capano (2003: 2-3) es el más adecuado para estudiar los paradigmas de políticas públicas. Por 14 otro lado, para un análisis detallado sobre el concepto de "sistemas de creencias" (belief systems), consultar Sabatier y Jenkins-Smith (1993). 
dinámicas de formación de la agenda de sus gobiernos y definición de los problemas identificados (Rochefort y Cobb, 1994), y explicar la elección de los diferentes mecanismos de regulación (Jordana y Levi-Faur, 2004), la política pública de regulación del servicio público de televisión (la variable dependiente), mediante la comprobación de hipótesis alternativas. Del mismo modo, el artículo comprobará el papel de las variables independientes tanto internas -tradiciones del Estado, ideas macro-económicas, filosofías de regulación, paradigmas de servicio público, papel de los gobiernos- como externas -globalización, desarrollo de las nuevas tecnologías, y, sobre todo, europeización- (Radaelli, 2005; Héritier et al, 2001). Se hace especial hincapié en el papel de las ideas (Hall, 1993; Mahoney, 2001), sistemas de creencias (Sabatier y Jenkins, 1993), y de los discursos dominantes dentro de las elites políticas en relación a los cambios de políticas de servicio público de televisión, dentro de un contexto institucional, tanto nacional como europeo.

El artículo propone una combinación novedosa de conceptos y teorías para el análisis del cambio en la fase de predecisión del proceso de elaboración de políticas públicas -definición del problema (Rochefort y Cobb, 1994) y formación de la agenda gubernamental (Kingdon, 1995)-; junto con la introducción necesaria del enfoque de europeización de políticas públicas (Radaelli, 2005; Héritier et al., 2001; Börzel, 2005, entre otros) como desafío metodológico para el análisis del cambio, permitiéndonos completar las dinámicas del sistema político británico en el período de estudio seleccionado.

El análisis se centra en las políticas de servicio público de televisión que ofrece la $B B C^{9}$. El caso del Reino Unido es relevante por dos razones, principalmente: por un lado, la $\mathrm{BBC}$ es el paradigma de la independencia y autorregulación del servicio público de televisión en el mundo. Por otro, es un modelo que tradicionalmente ha servido como motor de cambio en las políticas de servicio público de televisión en el conjunto de los Estados miembros de la UE y también en la esfera global. El ámbito de la política estudiada lo componen las siguientes variables, que en su conjunto constituyen la idea de servicio público de televisión en el Reino Unido: regulación del servicio público de televisión, organización y gestión, sistema de financiación, transparencia y rendición de cuentas y, por último, regulación de contenidos ${ }^{10}$.

9 Aunque a lo largo del texto me referiré a la BBC como corporación pública que ofrece un servicio público de televisión, es interesante resaltar que en el Reino Unido, servicio público de televisión se refiere tanto a canales de televisión comerciales (privados, diríamos en España) como públicos, con un alto grado de regulación de sus obligaciones por parte de diversas instituciones que se concentran desde el año 2003 en el regulador independiente Office for Comunnication (Ofcom). Recordemos que en España la Ley General de la Comunicación Audiovisual 7/2010, de 31 de marzo, contempla la creación de un Consejo Estatal de Medios Audiovisuales (CEMA) -único país de la UE que no lo tiene-. Sin embargo, a fecha de mayo de 2011 aún no se ha creado.

10 La regulación de los contenidos está en la esencia de la definición de servicio público y de su financiación en un mercado abierto a la competencia con otros operadores. El artículo no realiza un análisis de los contenidos que proporciona la BBC, sino del modelo regulatorio. De esta forma, se puede completar la distinción entre lo público y el resto. Es decir, ¿qué entiende la BBC por contenidos de servicio público? La programación se convierte en el resultado visible de la política de servicio público de televisión que se 
La investigación abarca el período que va desde 1979 hasta el año 2010. Se ha seleccionado este período de análisis porque en él se producen los cambios más importantes en el modelo de servicio público de televisión de la BBC, incluyendo períodos en los que Europa podría importar, por ser el Reino Unido miembro de la UE. En este periodo de la historia política británica, el servicio público de televisión se ha enfrentado a tremendos retos tales como la globalización, causada principalmente por la liberalización de las telecomunicaciones; la regulación de las telecomunicaciones a nivel nacional, europeo e internacional; el rápido avance de las nuevas tecnologías; y las propias dinámicas económicas, sociales, y políticas, así como las tradiciones y estructura del Estado británico; procesos de privatización y las políticas sobre la sociedad de la información. Todos estos retos se han identificado como problemas en un espacio de tiempo político específico (política), -con gobiernos conservadores, desde 1979 hasta 1997, y laboristas, hasta 2010- y con unas políticas bien construidas, dando lugar a cambios en el conjunto de las políticas de servicio público del país.

Las preguntas de investigación principales son las siguientes: ¿qué factores determinan el cambio en las políticas públicas de los sistemas políticos europeos? ¿Se han abierto ventanas de oportunidad para el cambio? ¿Se han aprovechado? ¿Son los cambios contexto-dependientes? ¿Es la formación de la agenda de los servicios públicos de televisión nacionales un proceso path-dependant-dependiente de un sendero ya marcado- o es permeable a cambios? ¿Nos sirve el modelo de las corrientes múltiples de Kingdon (1995) para explicar la evolución o cambio de las políticas del Reino Unido a través del estudio de las agendas de los gobiernos? ¿Qué papel han jugado las ideas en la definición de los problemas de políticas? ¿De qué depende que unos problemas se identifiquen como tal y se incorporen a la agenda de los gobiernos británicos en un servicio público tan reconocido a nivel mundial por su independencia tanto de los poderes políticos como de los económicos? ¿Qué papel juega la UE en el proceso de elaboración de las agendas de los gobiernos nacionales? ¿Qué papel juega la UE en la definición de los problemas (proceso, en nuestra opinión, clave para entender la formulación de las alternativas y toma de decisiones de las políticas públicas nacionales)? ¿Qué papel juegan las ideas que se construyen en el seno de la UE en las políticas públicas nacionales? ¿Si ha jugado algún papel la UE, cuál ha sido éste en el período estudiado, desde 1979 hasta 2010? De estas preguntas se han diseñado dos hipótesis principales: Hipótesis I: “La UE influye en el proceso de construcción de las agendas de las políticas de los servicios públicos de sus países miembros a través, principalmente, de su política de competencia. Parecería lógico que los servicios públicos de televisión a medio-corto plazo se redefinieran en esa dirección europea, salvo que los contextos nacionales tengan influencia para modificar la convergencia”. Hipótesis II:

resume en tres palabras: información, educación y entretenimiento. Para la BBC este es el orden y ha existido siempre una conciencia clara de uso del medio para la información y formación del ciudadano por encima del entretenimiento. Por el contrario, por ejemplo, el entretenimiento es el contenido más importante de RTVE. Europa también proporciona normas para la regulación de los contenidos audiovisuales que afectan tanto a la BBC, como a todos los operadores públicos europeos. 
"Los cambios, aunque las fuerzas de transformación fueran las mismas -Europa-, son contexto-dependientes".

En cuanto a la metodología, el artículo analiza las políticas de servicio público de televisión de un Estado miembro de la UE con una cultura original, con diferentes tradiciones en el modo de regularlo, de entenderlo y definirlo, dando lugar a un sistema político único.

Es importante resaltar que a la elección del caso británico para validar las teorías sobre el cambio, se añade el papel de la UE como actor participante necesario a tener en cuenta en los artículos de formación de las agendas y definición de los problemas de sus Estados miembros dentro del proceso de integración europea. La referencia a los actores domésticos en el centro mismo del problema coloca el proyecto más cerca de los enfoques de abajo-arriba (bottom-up) de los artículos de políticas públicas.

El marco de investigación propuesto sigue una estrategia analítica diacrónica pero también sincrónica. El caso británico se ha seleccionado teniendo en cuenta que es una democracia liberal estable, con una economía capitalista y con una cultura política democrática y un sistema administrativo racional (Jordan et al., 2003).

La presente investigación tiene en cuenta los actores más relevantes que intervienen en el diseño de la política de servicio público de televisión, los participantes, según Kingdon (1995): ministerios y departamentos gubernamentales competentes, las instituciones reguladoras independientes, académicos relevantes y expertos. Además, se tiene en cuenta al operador público de televisión BBC como policy subsystem (subsistema de políticas de Barzelay, 2006) tanto por ser una organización pública de un sistema institucional de regulación del servicio público, cuya gestión y titularidad pertenecen al Estado, encargada de implementar la política, como por ser un actor relevante del conjunto del sistema regulador institucionalizado, como proveedor de ideas y decisiones que aporta a la formulación de la política.

Es preciso destacar que la agenda de los gobiernos y la definición de las políticas de regulación del servicio público de televisión son aún dependientes de la propia historia institucional del caso estudiado. Al mismo tiempo, se han incorporado a las agendas de los gobiernos nacionales nuevas preocupaciones originadas por las dinámicas del proceso de integración europea. La UE podría tener un papel relevante en la definición de los problemas y en la formación de las agendas de los gobiernos de los Estados miembros. Así, a nuestro interés por el análisis del cambio en las políticas públicas domésticas en su etapa de predecisión -definición de problemas y formación de las agendas gubernamentales- se hace necesario añadir la variable europea.

Para el desarrollo de este artículo se han utilizado técnicas cualitativas de investigación social. Por un lado, fuentes secundarias, principalmente relacionadas con las políticas públicas y el estudio de las políticas de servicio público de televisión. La nueva evidencia empírica se basa en métodos de investigación en bibliotecas y archivos 
así como en entrevistas con políticos, expertos, académicos y responsables clave del desarrollo de la política británica. Se utilizaron entrevistas, no para recoger información sobre los hechos, sino para dibujar los sistemas de creencias y percepciones sobre las oportunidades y retos que los propios actores políticos tienen.

El artículo se estructura en varias secciones. En la primera, Marco conceptual y teórico e hipótesis, se realiza una revisión de la literatura sobre el análisis del cambio de las políticas públicas de Estados miembros de la UE. En una segunda sección, se presenta el Análisis de las políticas de servicio público de televisión en el Reino Unido de 1979 a 2010. Se finaliza con las Conclusiones a la luz de los datos expuestos.

\section{MARCO CONCEPTUAL Y TEÓRICO E HIPÓTESIS}

Como hemos expuesto anteriormente, el objetivo de esta investigación es el análisis de las políticas de servicio público de televisión del Reino Unido a través del análisis de la institución pública BBC desde 1979 hasta 2010, utilizando el enfoque de políticas públicas. En esta investigación interesa explicar el cambio en las políticas públicas nacionales objeto del estudio, teniendo en cuenta el proceso de integración europea.

En la literatura especializada sobre el análisis del cambio de las políticas públicas existen varias teorías, todas ellas complementarias e incluyentes ${ }^{11}$. Para el artículo de la política del servicio público de televisión británica se destacarán aquellas que ayudan a explicar mejor el cambio en la fase de predecisión de la política pública -la definición de los problemas y formación de las agendas gubernamentales. Sin embargo, en el desarrollo de la literatura existen carencias que es necesario cubrir mediante la introducción de la dimensión europea. La introducción de la variable UE, dentro del análisis del cambio a través del artículo de la etapa de predecisión de la política pública en sistemas políticos de Estados miembros de la UE, puede darnos una mejor comprensión de las políticas públicas dentro del proceso de construcción europeo. Así, aplicamos el enfoque de europeización ${ }^{12}$ como desafío metodológico al artículo del cambio de las políticas públicas. Este enfoque sirve para explicar el impacto que Europa podría tener en

11 Es interesante destacar que las teorías y marcos conceptuales que analizan los determinantes del cambio en políticas públicas se han nutrido fundamentalmente de teorías, conceptos y metáforas originales de otras disciplinas científicas, especialmente de la biología de la evolución humana (Gersick, 1991) y de la teoría de sistemas (Eldridge y Goul, 1972): desde el garbage can model de March y Olsen (1989) al primeval soup de Kingdon (1995), pasando por el punctuated equilibrium de Baumgartner (1993). En general, para explicar el cambio social, político o de políticas públicas, las ciencias sociales (sociología, economía, ciencia política, teoría de la organización, administración y gestión pública y otras) han utilizado teorías, conceptos y metáforas de otras disciplinas, especialmente de la biología, psicología, teoría de los sistemas y paleontología.

12 La literatura sobre europeización es ya muy extensa. A continuación se mencionan algunos de los textos de referencia: Radaelli y Saurugger (2008); Bulmer y Radaelli (2005); Börzel (2005); Featherstone y Radaelli (2003); Goetz y Hix (2001). Para una revisión crítica del concepto consultar, por ejemplo: Irondelle (2003); y Buller y Gamble (2002). 
las políticas públicas nacionales de distintos sistemas políticos. De esta forma, el análisis de dinámicas de políticas de países miembros de la UE será más completo.

A continuación se exponen las principales ideas del marco conceptual y teórico sobre el cambio, asimismo el enfoque de europeización de políticas públicas como desafío metodológico para su estudio. Además, se presentan las principales hipótesis que derivan de introducir en el análisis del cambio la variable UE que, a su vez, proviene del uso del enfoque de europeización de políticas públicas.

\section{1) Formación de la agenda y estudio del cambio: ideas y la política de definición de problemas}

De un modo general, existen varios marcos conceptuales y teóricos que tratan de explicar el cambio en el proceso de elaboración de las políticas públicas. Entre ellos cabe destacar el de las Coaliciones Promotoras o Advocay Coalitions (Sabatier, 1999, 1998; Sabatier y Jenkins, 1993, el llamado Comunidades del Conocimiento o Epistemic Communities (Haas, 1992), el modelo de las Corrientes Múltiples o Multiple Streams (Kingdon, 1995; Zahariadis, 2007) y el del Equilibrio Interrumpido'3 o Punctuated Equilibrium (True et al., 1999). Cada uno de los marcos conceptuales presenta condiciones específicas o procesos que explican tanto el cambio como la continuidad o estabilidad de la política pública considerada como la variable dependiente.

El artículo le da importancia a la fase de predecisión del proceso de elaboración de las políticas públicas, donde la definición de los problemas es una actividad relevante, consustancial con la etapa en la que se sientan las ideas para explicar el problema y buscar soluciones. Posteriormente, las ideas se introducen en la agenda y se sientan las bases para el cambio en la política pública. Dicho cambio puede observarse en la definición de los problemas que son el núcleo de la construcción de las agendas gubernamentales.

El trabajo considera las ideas como un conjunto de soluciones para los problemas de la política pública. Además, se tiene en cuenta desde un principio que las ideas, por sí solas, no cambian las políticas públicas. Sin embargo, las ideas son una fuente importante de cambio. Influyen en la percepción que sobre los problemas tengan los responsables de la toma de decisiones en el proceso de definición del problema y formulación de la política pública en un contexto institucional. El conjunto de las mismas, así como las creencias o marcos conceptuales crean paradigmas que compiten con otros en el proceso político, pero son los decisores públicos los que finalmente las introducen en el proceso de definición de los problemas, los introducen en la agenda y, a partir de ahí, se produce la formación de la política pública, es decir, que los intereses de los actores son también variables esenciales.

13 El concepto proviene de la teorización sobre el cambio llamado "punctuated equilibria" de Baumgartner y Jones (1993). 
En 1999, K. Sikkink percibió que es una paradoja que los académicos, cuya existencia está centrada en la producción y comprensión de ideas, le den tan poca importancia a las mismas para explicar la vida política (citado en Mark Blyth, 2002: 17). En ese sentido, Blyth (2002: 17) añade que la fuente de esa paradoja se encuentra en la forma en la que la ciencia política contemporánea ha conceptualizado la relación entre instituciones, intereses e ideas. Por su parte, Majone nos advierte sobre la importancia de las ideas. Cuenta este autor (2001: 887) que unos treinta años atrás, Lindblom criticó el tosco realismo de pluralistas como Arthur Bentley, quien desechó la importancia de las ideas en la política y argumentó “como si las mentes estuvieran entre los más triviales de los recursos a disposición del grupo” (Lindblom, 1965: 16).

Como se apunta más arriba, las ideas son fuente de cambio pero no lo provocan por sí solas. De este modo, las mismas se deben contextualizar dentro del proceso de definición de los problemas así como de la construcción de las agendas gubernamentales. Por ello realizamos la siguiente pregunta, con el ánimo de resaltar la importancia del estudio de las agendas en la explicación del cambio de un modo más concreto, ¿por qué es importante el estudio de las agendas gubernamentales? Se toma como referencia para su respuesta, entre otras, las ideas de uno de los trabajos más citados en el estudio de las agendas. Se trata del trabajo de Baumgartner et al. (2006), en el que sus autores exponen que el estudio de la formación de las agendas y dinámicas de políticas públicas es una tradición investigadora bien asentada que nos lleva atrás en el tiempo a los trabajos clásicos de Bachrach y Baratz (1962) y Schattschneider (1960). Dicen, además, que la tradición investigadora proporciona cuantiosas ideas sobre cómo los cambios en la agenda y la atención política afectan a la política pública. Es decir, el estudio de las agendas nos sirve para estudiar el cambio en las políticas públicas que, a su vez, influye en el resultado final, al menos en esta fase de predecisión. Sin embargo, siguen los mismos autores, la tradición investigadora ha estado dominada por estudios sobre los Estados Unidos y ha sufrido una carencia de estudios comparados.

Cómo se definan los problemas públicos afecta fuertemente a las políticas públicas; y esa definición contiene ideas ${ }^{14}$. Las estructuras normativas y cognitivas, las creencias y las ideas de los decisores públicos aparecen, así, adecuadas para explicar la evolución y el cambio de las políticas de servicio público de televisión en un escenario europeo. Aunque, como veremos más adelante, éstas no son las únicas. La definición del problema de políticas de servicio público de televisión en el Reino Unido está en el centro de esta investigación ya que se entiende que este proceso ilustra bien que las soluciones de políticas dependen enormemente de la forma en que se percibe el problema. Cómo se ha percibido el problema ya ha tenido lugar cuando el tema 气 $\quad$ llega a la agenda. Además, aquel que forma la agenda tiene el poder de delimitar la

14 De acuerdo con Peters (1994: 12), la construcción de las agendas no consiste únicamente en la consideración de un tema por parte de los gobiernos de forma activa; es también sobre cómo ese tema se define una vez que entra en la agenda. Por ello, la definición del problema nos ayuda a comprender qué soluciones de políticas se han dado a un problema concreto, determinando el alcance y las alternativas dentro de un periodo histórico y un proceso de formulación de políticas dado. 
definición del problema y la formulación de la política. La definición original del problema no solo influye en las alternativas que se consideren finalmente, sino que limita el debate. Las ideas sobre cómo se define un problema dan forma a las soluciones de políticas y, quizás, influyan en los procesos de cambio institucional. El debate sobre por qué, qué, cómo y cuándo se adopte una alternativa de políticas es el tema de esta investigación.

Dentro del proceso mencionado anteriormente, ¿cuál es el poder de la UE? ¿Cómo se podría realizar un seguimiento de su influencia e impacto en la definición de los problemas a nivel nacional? Adicionalmente, no existen estudios sobre el papel de la definición de problemas, de las estructuras cognitivas y normativas, y de las ideas en el desarrollo y cambio de las políticas de servicio público de televisión en Europa. Sin embargo, desde los años 80, el concepto de definición de problemas se ha aplicado como instrumento analítico para explorar la evolución y el cambio de políticas en una gran variedad de temas (policy issues) tales como pensiones (Elder y Cobb, 1975), agricultura (Mucciaroni, 1994) transportes (Baumgartner y Jones, 1994; Coughlin, 1994), VIH / SIDA (Rochefort y Cobb, 1994a), y administración pública (Weiss, 1989).

La literatura sobre definición de problemas ofrece una estructura conceptual robusta y diversa para comprender la formación y el cambio de las políticas. Dicha literatura utiliza diferentes modelos y le da importancia a determinados aspectos, por ejemplo, la noción de Kingdon sobre la intersección de corrientes de políticas públicas que se juntan en un momento crucial (1995: 165-171), el concepto de historias causales ("causal stories") de Stone (1989) o la perspectiva de imágenes sociales ("social images") de Rochefort (1994a). Este último autor argumenta que las definiciones de los problemas sociales corresponden habitualmente a las diferentes imágenes que tienen los grupos necesitados. A pesar de la diversidad encontrada en la literatura, es posible identificar ciertas características comunes: 1 ) la importancia de los actores en la producción de las definiciones de los problemas; 2) el papel determinante de las ideas en el proceso de elaboración de las políticas; 3) el uso de lenguajes y símbolos para definir los problemas; 4) la existencia de una relación entre problemas y soluciones; 5) la naturaleza estratégica y subjetiva de la definición del problema. El caso analizado en este trabajo examina estos cinco elementos para comprender cómo la definición de problemas contribuyó al desarrollo y al cambio de las políticas de servicio público de televisión a través del estudio de las ideas en cada gobierno seleccionado.

En la literatura se observa además una conceptualización dual sobre la definición de problemas. Por un lado, se entiende la definición de problemas como un proceso dentro del largo camino de la elaboración de la política y, por otro, como un producto del proceso de elaboración de la política, al que le da forma ese proceso, al tiempo que este da forma al propio proceso. Estos dos aspectos de la definición de la política no se excluyen, sino que se refuerzan mutuamente y, en conjunto, demuestran el complejo papel de la definición de problemas en la elaboración de las políticas. 
El concepto de definición de problemas como subproceso dentro del largo proceso de elaboración de la política es evidente en muchos de los trabajos que abordan la construcción o elaboración de la agenda. Entre ellos cabe destacar el de Cobb y Elder (1975), Baumgartner y Jones (1994), Rochefort y Cobb (1994) y Kingdon (1995). Estos trabajos presentan la definición de problemas de forma típica, como parte del proceso de elaboración de la política en el que los decisores públicos comienzan a identificar un conjunto de condiciones como un problema y consideran que se deben tomar medidas para solucionarlas (Kingdon, 1995: 109; Rochefort y Cobb, 1993: 5758). De ese modo, la definición del problema es un proceso que traslada los problemas a la agenda de políticas (Cobb y Elder, 1975: 89-95; Baumgartner y Jones, 1993: 25-29), así como un proceso que ayuda a enlazar problemas con soluciones de políticas (Baumgartner y Jones, 1993: 27; Dery, 2000: 40). Esto no significa necesariamente que la definición del problema sea una fase de la política discreta y claramente identificable dentro del proceso de elaboración de la política; de hecho, el concepto de un proceso de elaboración de políticas nítido y ordenado en fases se ha rechazado por la mayoría de los escritos encontrados en la literatura sobre políticas públicas. Al contrario, las definiciones sobre problemas cambian y evolucionan a través del proceso de elaboración de la política (Rochefort, 1994: 18) y el mismo problema puede aparecer nuevamente, incluso después de que los decisores lo hayan resuelto aparentemente (Cobb y Elder, 1975: 158). Así, de alguna forma la definición de problemas es un proceso continuo en el que los decisores suelen ocuparse del mismo tema repetidamente. Europa no aparece en un principio de forma clara como fuente de cambio dentro del proceso de definición de problemas. Sin embargo, la técnica de entrevistas semiestructuradas a los responsables de la toma de decisiones de la política en cuestión podría permitirnos averiguarlo.

El caso seleccionado en esta investigación tiene en cuenta la definición de problemas, tanto como proceso como producto del proceso de elaboración de la política. Las ideas, dentro de un escenario institucional y un proceso de integración europea se convierten, así, en elementos relevantes para explicar el origen, desarrollo, persistencia y cambio. Sin embargo, existen carencias en los análisis de políticas públicas de Estados miembros de la UE. Es necesario introducir el enfoque de europeización de políticas públicas para completar el dibujo del cambio doméstico dentro del proceso de integración europea. La siguiente sección abordará las limitaciones que tienen los enfoques de definición de problemas y formación de la agenda en un escenario europeo.

\section{2) Europeización e Integración Europea: un desafío metodológico sobre el análisis del cambio en el estudio de las políticas públicas}

Desde hace aproximadamente quince o veinte años existe un vivo debate sobre qué es europeización y cuál es su poder sobre las políticas domésticas. Tradicionalmente, estudios de la UE han examinado los cambios que se producen en las políticas 22 de regulación (incluyendo la regulación de los medios de comunicación) a nivel nacio- 
nal analizando los efectos de las directivas de la UE, la política de la competencia y el impacto de las decisiones del Tribunal Europeo de Justicia. De manera alternativa, los análisis clásicos de política comparada explican qué hacen los diferentes gobiernos y porqué, pero rara vez tienen en cuenta la europeización y cuando lo hacen lo tratan como una variable más que interviene. En el primer caso, existe el riesgo de sobreestimar el papel de la política de la UE. Por otro lado, el caso de los clásicos artículos de política comparada es más prometedor, pero es necesario reconocer desde el principio que europeización puede ser tanto una variable independiente como dependiente. La pregunta es ¿cómo podemos medirla? Este proyecto comienza desde el terreno doméstico, desde sus actores en el centro mismo del problema, y persigue preguntarse si y cuando el proceso de europeización ha jugado algún papel, y si es así cómo (una re-definición de los problemas políticos domésticos, como generador de nuevos problemas políticos, como un recurso ideológico, como generador de cambio en las estructuras políticas domésticas, o como un impedimento sobre el proceso de realización de las políticas). El énfasis en el 'cómo' sitúa este artículo dentro de la nueva generación de trabajos sobre europeización, basados no tanto en el 'Europa importa', sino 'cómo importa'.

El marco conceptual y teórico, así como metodológico, del presente artículo realiza una conexión entre europeización de políticas públicas, proceso de integración europea y su relación con la definición de los problemas y formación de las agendas de los gobiernos de los Estados miembros de la UE. Todas estas conexiones se tienen en cuenta como procesos que podrían influir en el cambio de las políticas públicas nacionales y, por tanto, en su resultado final, al menos en la fase de predecisión estudiada. Interesa entender europeización como un desafío metodológico en el estudio del cambio en las políticas públicas de los Estados miembros de la UE.

Europeización debe tenerse en cuenta dentro del contexto de la integración europea y sus dinámicas políticas, de las políticas públicas y de las transformaciones de las estructuras del Estado como entidad política soberana ("policy", "politics", y "polity"). Debe considerarse, además, que no existe un único enfoque o disciplina capaz de explicar las complejidades de las dinámicas de la integración europea (Dehousse y Majone, 1994) -citados por Olsen (1996). Esta investigación se acerca a europeización como un enfoque distinto y distintivo, como una metodología útil y un proceso dinámico para explicar las claves de los cambios en las políticas públicas nacionales como impactos del proceso de integración europea. Este enfoque es complementario a los artículos tradicionales de políticas públicas en un entorno europeo.

Como escriben Morata y Mateo (2007: 4) “la literatura sobre ‘europeización’ ha experimentado un considerable desarrollo en los últimos años (Cowles, Caporaso y Risse, 2001; Börzel 2001; Featherstone y Radaelli, 2003; Bulmer y Lequesne, 2005; Graziano y Vinck, 2007). Sin embargo, a pesar del interés despertado por dicho concepto, todavía resulta prematuro hablar de una teoría en sentido estricto (Bulmer, 2007)". Como dice Radaelli (2005: 2) para la más reciente generación de artículos, la europeización no es una nueva teoría, tampoco es solamente un enfoque, sino que es una 
nueva forma de teorización con nuevo vocabulario que permite orquestar los conceptos y teorías existentes; europeización no es un Estado, sino un proceso sistémico donde se correlacionan inputs (variables europeas independientes) y outputs (impactos domésticos); europeización puede proveer el contexto, la cognición y la normativa "marco", es decir, los términos de referencia de los actores domésticos que producen cambios $\mathrm{y}$, por último, europeización puede ser considerada como un mecanismo de amortiguación del impacto de la homogeneización de la UE sobre instituciones y prácticas específicas en un amplio rango de actividades estatales, pues europeización no supone convergencia. La presente investigación se centra en ese contexto, cognición y normativa "marco", es decir, en los términos de referencia de los actores domésticos que producen cambios en sus políticas y regulación de sus servicios públicos de televisión en la fase de predecisión -definición y formación de la agenda, y en los impactos de la europeización en esos marcos cognitivos.

Europeización no trata del estudio sobre la conformación de la UE como poder político, análisis propio de las teorías de integración supranacional e intergubernamental. Se entiende que la UE ya existe como un actor político, que es, además, sui-generis. Produce decisiones e impactos (cambios y ajustes) sobre las políticas domésticas así como en los estilos de regulación dominante y las estructuras de ciertos sectores de política de los Estados. El interés teórico de este enfoque se centra en la conexión entre integración europea y las políticas domésticas, es decir, en los conceptos de europeización de los Estados y la europeización de políticas e instituciones domésticas. Este tipo de análisis requiere de cierta sofisticación ya que se debe encontrar un modelo de impacto de la integración europea sobre las políticas domésticas sabiendo que, al mismo tiempo, éstas son el mayor factor explicativo del cambio de la política de la UE. Es decir, europeización también se entiende como un asunto de reciprocidad, donde la atribución de impacto doméstico no siempre es fácil, ya que los límites entre causa y efecto y variables dependientes e independientes son a menudo difusos.

Otra de las características que muestra Radaelli (2005: 4), y que según él distingue europeización de otros enfoques al artículo de los procesos políticos en Europa, es la ausencia de hipótesis sobre convergencia. Las investigaciones sobre europeización proporcionan más ejemplos de divergencia que de convergencia. Europeización está interesada sobre todo en la adaptación a Europa, sin realizar grandes predicciones. Las instituciones a nivel nacional se suponen que son maleables en diferentes grados, pero no desaparecen (Börzel, 1999; Héritier et al., 2001).

En relación al concepto de europeización, se debe decir que ninguna definición es enteramente satisfactoria para describirlo15. De forma sencilla se podría definir

15 No es el propósito de este artículo definir qué es o no europeización. Más bien, el trabajo se presenta como una contribución a ese debate mediante pruebas que demuestren el impacto de la UE en una política pública concreta. Es esencial la realización de más investigaciones exhaustivas y con una pers- 
europeización como el papel que quizás juega la UE en el cambio de las políticas públicas, la política o en las estructuras o formas políticas en el nivel doméstico o nacional. Sin embargo, esto no es del todo acertado ya que hablar de europeización es hacerlo de múltiples y diversos procesos, de procesos de retroalimentación y conflicto, de enfoques y de método.

Para esta investigación la definición dada por el profesor Radaelli es la más completa: "La europeización consiste en procesos de (a) construcción, (b) difusión y (c) institucionalización de reglas formales e informales, procedimientos, paradigmas de políticas públicas, estilos o 'formas de hacer las cosas', y de creencias y normas compartidas que inicialmente se definen y consolidan en el proceso político de la UE para ser incorporados posteriormente en la lógica del discurso doméstico (nacional y subnacional), las estructuras políticas y las políticas públicas".

Radaelli explica que, como construcción, europeización estaría cambiando la comprensión de la gobernanza en Europa y estaría modificando su noción en los Estados; como difusión estaría actuando de vehículo a través del cual los discursos europeos son institucionalizados en las políticas domésticas; y como institucionalización estaría haciendo emerger distintas estructuras de gobernanza. Los resultados preliminares de la investigación nos muestran un cambio en las políticas del servicio público estudiado en este sentido del término europeización, aunque las distintas soluciones adoptadas en el Reino Unido, tienen que ver también con su evolución histórica, y ahí, en ese decoupling, el institucionalismo histórico nos puede ayudar a completar la explicación.

Una alternativa para explicar el proceso de europeización de las políticas de servicio público de televisión se podría realizar mediante el uso de conceptos y teorías provenientes de la literatura relacionada con los procesos de lesson drawing (aprendizaje) y de transferencia de políticas (policy transfer). La literatura sobre transferencia de políticas, difusión, convergencia y de lesson drawing encaja bien con el proceso a través del cual se define y formula la política de la UE. El tema común dentro de estos estudios es la preocupación por el conocimiento sobre cómo las políticas, los convenios administrativos, instituciones e ideas en un contexto político (pasado o presente) se utilizan en el desarrollo de políticas, convenios administrativos, instituciones e ideas en otros contextos políticos (Dolowitz y Marsh, 2000: 5). Este es un campo de indagación interesante para comprender la aportación del caso británico, aunque esta investigación avanza un paso más y considera los impactos de la UE, una vez que el proceso ha tenido lugar. Nuestra investigación aprecia la importancia de la formación de la política de la UE. De hecho, ese proceso explica de dónde podrían provenir las ideas como parte de esa interacción entre los Estados miembros y la UE. Sin embargo, entendemos en este estudio que europeización está más interesada en la naturaleza de los impactos, una vez que ya existe una política de la UE.

Por otro lado, Börzel (2005: 19-23) ofrece un concepto interesante para explicar la relación entre la UE y sus Estados miembros. Explica la autora que los Estados miem- 
bros no son meros receptores pasivos de demandas europeas determinantes del cambio doméstico, sino que actúan de forma proactiva en la formación de políticas europeas, instituciones, y procesos a los que tienen que adaptarse después (cita la autora a Bomberg y Petersons, 2000; Wallance, 1971; y Héritier et al., 1994). Además, sigue Börzel, la necesidad de adaptarse a las presiones europeas a nivel doméstico podría tener efectos de retorno significativos a nivel europeo, donde los Estados Miembros buscan reducir el desencaje (misfit) entre acuerdos domésticos y europeos. Otro de los interesantes argumentos es que una estrategia efectiva de maximización de beneficios y minimización de costes de las políticas públicas europeas es introducir de forma consciente (up-load), o exportar las políticas nacionales en el nivel de la UE. Esta estrategia reduciría la necesidad de adaptarse legal y administrativamente, ya que las mismas políticas se estarían practicando a nivel nacional. Esto último, bien dice, es una estrategia en relación a una acción proactiva. Este proceso de "up-loading", o transferencia de políticas desde los Estados miembros hacia arriba, hacia la UE, podría ayudarnos a entender la europeización de nuestro caso de estudio. Sin embargo, no nos ayuda a comprender el impacto de la UE en las políticas de sus Estados miembros.

Por último, uno de los aportes más interesantes es que Europeización proporciona un marco metodológico novedoso que el presente artículo entiende como un desafío en el estudio del cambio en las políticas públicas. En relación a este punto, estamos de acuerdo con las aseveraciones que realiza también el profesor Radaelli (2003: 28) cuando dice que no hay necesidad de inventar teorías o modelos ad hoc que no vayan más allá de la europeización. Justo lo contrario, el objetivo es mostrar cómo varios aspectos importantes de la europeización se pueden manejar mediante el uso de análisis estándar de conceptos y metodologías provenientes del análisis de políticas comparadas. Además, este estudio añade que para explicar la etapa de predecisión de las políticas públicas comparadas en un contexto europeo -las políticas de definición de problemas y la construcción de la agenda- tanto en su continuidad como en su cambio, es necesario utilizar el enfoque de europeización de políticas públicas y combinarlo con las teorías y conceptos provenientes de los estudios de dinámicas de políticas públicas que hemos revisado anteriormente.

En esta investigación, el del cambio en las políticas públicas de los Estados miembros a través del enfoque de europeización ayuda a comprender mejor que papel juega Europa, si es que juega algún papel, y qué impacto tiene el mismo en las políticas públicas domésticas o nacionales, para completar el artículo de las dinámicas políticas a nivel nacional. La pregunta que intentamos responder aquí es cómo podemos estudiar los procesos de europeización y el impacto que producen los mismos en el cambio de las políticas públicas.

Este enfoque es necesario para explicar las dinámicas e impactos de Europa en las políticas públicas domésticas o nacionales, y de ese modo explicar, además, las dinámicas del proceso de integración europea, siempre como complementario a otras dinámicas tanto internas como globales. Dür y Mateo (2004: 16-17) aciertan en 26 destacar que la originalidad de este nuevo enfoque está en que las instituciones su- 
pranacionales han dejado de ser la variable dependiente y el nivel doméstico ha pasado a asumir este rol (Green et al., 2001; Börzel, 2002; Olsen, 2002; Schmidt, 2002; Featherstone, 2003, citados en Dür y Mateo (2004: 17).

Por otro lado, es útil acercarse al enfoque de europeización más allá de una noción de impacto linear, estrecha, o top-down (de la UE en los sistemas políticos nacionales). La idea de impacto es de alguna forma estática y mecanicista, mientras que el mundo real de los procesos de europeización proporciona oportunidades considerables para usos creativos de Europa. Los actores domésticos pueden usar Europa de muchas formas y de manera discrecional. Quizás crean impactos discursivos. Quizás utilizan a Europa como un recurso, incluso en ausencia de impactos. Europeización se ocupa de cómo se procesa el cambio en el nivel doméstico, y los modelos de adaptación pueden ser más complejos que una simple reacción al “impacto” (Radaelli, 2005: 6).

El elemento central del enfoque teórico de la europeización es la noción de impactos domésticos, a pesar de lo cual el análisis de esta dimensión constituye todavía un terreno relativamente inexplorado según el profesor Radaelli (2008). Un problema importante en este sentido es la falta de un marco de explicación comprehensivo de la adaptación doméstica transversal a las políticas y los países. Sin embargo, como la europeización de la política pública puede afectar a todos los elementos básicos del proceso (actores, recursos e instrumentos políticos) y los estilos políticos, los diseños de investigación distinguen entre impactos sobre los elementos del proceso de política, impactos sobre los marcos cognitivos y normativos e impactos en el nivel de resultados de la política. La definición de los problemas adquieren en este sentido enorme importancia para nuestro análisis, como determinante del resultado final de la política. La investigación se centra en el impacto en el marco cognitivo y normativo, en las ideas, dentro de un marco institucional y dentro del proceso de formación de las agendas gubernamentales.

En este punto es necesario destacar el enfoque metodológico que aporta europeización con respecto a los estudios anteriores sobre el proceso de integración europea. Radaelli (2005: 32) muestra un gráfico en el que se observan tres enfoques: integración europea, europeización top-down y europeización bottom-up:

$$
\text { GRÁFICO } 1
$$

Del estudio del proceso de integración europea al estudio de sus impactos

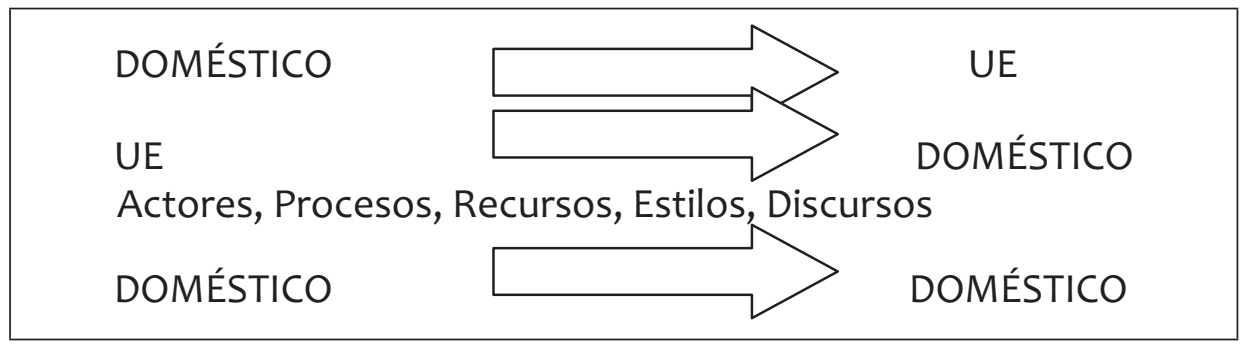

Fuente: Radaelli (2005). 
Nuestro enfoque metodológico, para completar los estudios de políticas públicas en un entorno europeo, es el representado por la tercera flecha, que muestra un diseño de investigación bottom-up. Este diseño comienza en los actores, problemas, recursos, estilos y discursos en el nivel doméstico. Mediante el uso de secuencias temporales y causales, un enfoque bottom-up comprueba si, cuándo, y cómo la UE proporciona un cambio en cualquiera de los componentes del sistema de interacción. Aquellos que utilizan este enfoque intentan medir las consecuencias como cambio a nivel doméstico. Esto podría llevarnos a verlo como otro mecanismo de "impacto", pero con la diferencia de que la noción de impacto va más allá de la "reacción" a Europa e incluye usos creativos (Radaelli, 2005: 7). La dimensión Europa es el aporte necesario que en una secuencia temporal de medio y largo plazo puede ofrecernos una explicación más completa de los cambios en las políticas domésticas.

Adicionalmente, Radaelli (2005: 24) cree que es preciso tener en cuenta tres puntos de vista importantes para el análisis del impacto doméstico: a) hay europeización cuando la lógica de los actores domésticos cambia y se piensa en Europa como la "gramática” de la acción política doméstica (Europa como lógica y marco); b) europeización es cambio en ambas direcciones, en el sentido de respuesta a las medidas de la UE y en el sentido de respuesta a otros actores de Europa (Europa como cambio) y c) europeización como proceso que consiste en complejas secuencias y evolución de tiempos (Europa como análisis del tiempo). Otros aspectos fundamentales del análisis de impacto doméstico son los mecanismos y los resultados del cambio. En cuanto a los mecanismos de cambio doméstico, la literatura sobre europeización los clasifica en impactos domésticos de Europa como proceso de redistribución de recursos, como proceso de socialización y como proceso de adaptación institucional.

El enfoque sobre los impactos de adaptación institucional es útil para nuestro caso. Estos impactos domésticos de Europa pueden variar según el nivel de presión de la adaptación europea sobre las instituciones domésticas y según el contexto doméstico, que puede facilitar o dificultar los acuerdos. Las instituciones de la UE, como fuente de nuevas normas, reglas, prácticas y estructuras de significados, pueden redefinir las instituciones domésticas mediante mecanismos de coerción, imitación mimética, selección competitiva y "estructuración" ("framing"), por lo que es fundamental conocer si los cambios están correlacionados o causados por europeización y no por otras variables, evitando el peligro de prejuzgar el impacto de europeización. El problema está mediatizado por la estrategia de los líderes políticos para disfrazar la globalización (Hirst y Thomson, 1996) las políticas domésticas bajo un discurso de europeización, como una manera de buscar culpables o por usar el nombre de Europa para sumar legitimidad a los cambios. En nuestro estudio, sorprendentemente no se aprecia ninguna utilización de Europa para explicar los cambios a nivel doméstico, cuando, quizás, sea Europa una de las fuentes de cambio.

A pesar de la escasa evidencia empírica sobre la convergencia de instituciones, políticas y procesos, en nuestro caso de artículo se aprecia una convergencia ideacio28 nal. Las reformas aparecen en principio soluciones nacionales a problemas naciona- 
les, sin embargo, es posible que la UE haya tenido algún papel relevante con resultados tanto divergentes como convergentes.

\section{3) Hipótesis}

Como hemos observado anteriormente, existe una relación entre el proceso de integración europea y el proceso de elaboración de las políticas públicas nacionales. Sin embargo, las teorías que analizan los procesos de elaboración de las políticas nacionales en su etapa de predecisión -definición del problema y construcción de la agenda- de países miembros de la UE no tienen en cuenta esta relación tal y como la presenta el diseño de investigación que propone europeización. Es decir, este diseño comienza en los actores, problemas, recursos, estilos y discursos en el nivel doméstico. Mediante el uso de secuencias temporales y causales, un enfoque bottom-up comprueba si, cuándo, y cómo la UE proporciona un cambio en cualquiera de los componentes del sistema de interacción.

Así, para explicar el cambio de las políticas de servicio público de televisión del Reino Unido -Estado miembro de la UE desde 1973- la combinación de los conceptos y teorías sobre definición de problemas ${ }^{16}$ y formación de las agendas gubernamentales y la dimensión europea nos ayudan a diseñar hipótesis más completas. Nos planteamos la siguiente pregunta en relación a la importancia de introducir la dimensión europea: ¿por qué es importante el estudio del cambio a través del análisis de los procesos de definición de problemas y construcción de las agendas en el sector específico de las políticas de servicio público de televisión en un Estado miembro de la UE?

La pregunta anterior tiene relevancia porque nos planteamos la necesidad de tener en cuenta en los estudios de políticas públicas de países miembros de la UE las dinámicas de europeización que se generan en el proceso de integración europea. El diseño de investigación no se centra en el proceso de construcción de la agenda de la UE. Ni tampoco en las políticas de definición de problemas en el seno de la Unión.

A pesar de la importancia del estudio de la formación de la agenda de la UE (Zahariadis, 2007, Sabatier, 2007; Corbett, 2005; Princen, 2007; Albæk, 2004; Considine, 1998; Green-Pedersen, 2007; Soroka, 2007; Peters, 2001; Pollack, 1997; Princen y Rhinard, 2007; Tallberg, 2003), la cuestión de qué hace que el proceso de integración europea esté activo, el origen de sus dinámicas integradoras gubernamentales o neofuncionalistas unidas a ese proceso, no es el motivo de nuestra investigación. En nuestra investigación no nos interesa tanto el proceso de formación de la agenda de la UE, o de manera más individualizada de sus instituciones, como la Comisión Europea, sino, una vez que ésta se ha formado o incluso en su proceso de formación, qué impacto tiene a nivel nacional o doméstico. Nos interesa, por tanto, el estudio de los

16 La bibliografía sobre definición de problemas, como proceso o como producto, es muy amplia. Baste mencionar dos trabajos esenciales: Rochefort y Cobb (1994) y Schön y Rein (1994). 
impactos, avanzando un paso más en el campo de los estudios de formación de la agenda en un entorno europeo. Baumgartner et al. (2006: 967) citando a Princen (2007), dicen que está muy claro que las dinámicas de las agendas son elementos importantes sobre cómo funciona ese proceso, tanto dentro de la UE como entre la UE y sus Estados miembros.

En este punto, el artículo plantea la primera hipótesis teniendo en cuenta las teorías que explican el cambio pero añadiendo los procesos de europeización y su diseño de investigación:

Hipótesis I: La UE influye en el proceso de construcción de las agendas de las políticas de los servicios públicos de sus países miembros a través, principalmente, de su política de competencia. Parecería lógico que los servicios públicos de televisión a medio-corto plazo se redefinieran en esa dirección europea, salvo que los contextos nacionales tengan influencia para modificar la convergencia.

El proceso de construcción de las agendas gubernamentales, las ideas, la definición de problemas, la estabilidad o cambio de las políticas públicas se enmarcan dentro de un proceso de integración europea, donde el enfoque de europeización de políticas públicas nos podría aportar el marco necesario para poder explicar con mayor precisión los casos estudiados. Además, podría aportarnos algunas claves para el futuro de los estudios sobre políticas públicas en un entorno europeo. Así pues, el enfoque de europeización de políticas públicas es, a nuestro entender, un aporte clave de nuestra investigación.

Finalmente, conocer el proceso de construcción de las agendas podría contribuir a comprender mejor el proceso de construcción europeo en su conjunto. Dada la naturaleza evolutiva de la UE, la cuestión sobre qué determina el avance del proceso de integración europea ha sido un aspecto central de los artículos de la UE. El reto de esta investigación es explicar el grado de integración europeo. Es decir, el estudio de la relación de la agenda de la UE con la de sus Estados miembros podría ser útil para conocer el impacto de la UE en los procesos de gobernanza en Europa.

La presente investigación intenta dar respuesta a cómo se desarrolla el proceso de formación de la agenda gubernamental del Reino Unido, dándole gran relevancia a los procesos de definición de problemas. En concreto, importa el proceso de formación de la agenda de las políticas de sus servicios públicos de televisión. Con ello, se pretende analizar cómo los cambios en la agenda y la atención política afectan a esas políticas públicas. Para ello utilizaremos el modelo teórico de las Corrientes Múltiples (Multiple Streams Model) de Kingdon (1995). El modelo nos servirá para responder a las preguntas de investigación y validar hipótesis. Las corrientes (streams) o procesos mencionados los agrupa Kingdon en problemas, políticas (policy) y política. La investigación le da importancia a las ideas, a la identificación y definición de los problemas; al proceso de las políticas de regulación de los servicios públicos de televisión; y, a qué papel juega la política en esos procesos. Al estudio de los procesos de problemas, 
política y políticas a nivel doméstico o nacional, le añadimos el entorno europeo, o proceso de integración europea, utilizando un enfoque metodológico más completo para el análisis del impacto de Europa en las políticas públicas nacionales, el llamado enfoque de europeización de políticas públicas. Este artículo utiliza la teoría de Kingdon (1995) ya que proporciona una forma de analizar la fase de predecisión a través de la definición de problemas y formación de la agenda: el análisis del proceso por el cual se especifican las alternativas en el que las ideas se refinan y combinan hasta que se presentan como la elección de política pública recomendada para los decisores políticos -o si algo ha sucedido para que el proceso se pare. El concepto de especificación de las alternativas ayuda a investigar el proceso político. En este punto es necesario tener en cuenta el enfoque metodológico propuesto para, en la raíz del problema, a nivel doméstico o nacional, comprender mejor las dinámicas del proceso de integración europea.

El conjunto de conceptos y teorías propuesto por Kingdon, unido al enfoque de europeización de políticas públicas, nos ayudará a comprender mejor la evolución y el cambio de modelo de política de servicio público de televisión británico. Específicamente, nos ayudará a comprender por qué unos temas se incluyen en la agenda de decisión de los gobiernos y por qué otros no, cuándo y cómo, además de identificar las ideas que se concretan en el resultado final de la definición del problema y selección de la opción elegida. Y es en éste punto donde se produce la innovación de la presente investigación, aportando a las teorías de Kingdon un "participante" más en el proceso de formación de las agendas e identificación y definición de los problemas a nivel doméstico o nacional: la UE.

La teoría de Kingdon se utiliza para analizar la trayectoria de una idea en la fase de predecisión del proceso de formación de la agenda. Kingdon concede una relevancia singular al análisis del proceso de especificación de las alternativas, en el cual las ideas se perfeccionan y combinan hasta que se presentan como la mejor elección para los responsables de la toma de decisiones. En éste último proceso, la definición de los problemas entra en la fase de formación de la agenda, considerándola como elemento relevante del mismo, dado que es donde se produce una acotación de las alternativas. El concepto de especificación de las alternativas nos permite también investigar el proceso político, clave en el cambio de las políticas del Reino Unido. Kingdon nos ayuda también a identificar los mecanismos de cambio de las políticas públicas analizando la actividad de los "policy entrepreneur", los cuales aprovechan las oportunidades de influenciar de una manera apropiada la fase de desarrollo de la política pública. Así, la investigación se basa en estas ideas y en ciertos elementos del institucionalismo histórico para explicar el desarrollo de la política de servicio público de televisión en los términos del proceso dibujado por Kingdon, añadiendo una relación analítica con el proceso de europeización.

Kingdon nos ayudará a comprender mejor si se producen cambios en el modelo de política de servicio público de televisión del caso británico. Específicamente, nos ayuda a comprender por qué unos temas se incluyen en la agenda de decisión de los 
gobiernos y por qué no otros, cuándo y cómo. Sobre todo, qué papel juega la UE en el proceso de definición de problemas y qué impacto tiene en las políticas domésticas. De esta forma podemos averiguar "at the hub of the problem" (en el centro del problema) si Europa ha jugado un papel, cuándo, cómo, y porqué. En concreto, estudiaremos cómo influyen las ideas de la UE en la formación de la agenda de las políticas de servicio público de televisión del Reino Unido. Con una hipótesis de partida, influyen pero no pueden obviar la estructura institucional interna, el cambio es contexto-dependiente. El trabajo de Kingdon (1995: 2) contribuye a un entendimiento más completo de estos procesos de predecisión de políticas.

Además, como el propio Kingdon (1995: 165) indica, la apertura de ventanas es una oportunidad para que los distintos actores o defensores de políticas intenten introducir sus soluciones favoritas, o para atraer la atención sobre sus problemas particulares. Verdaderamente, estos defensores están dentro y alrededor del gobierno con sus soluciones en la mano, esperando a que surjan problemas para los cuales ellos tienen su solución, esperando a que la corriente de política se desarrolle en su beneficio. Algunas veces la ventana se abre de forma predecible, aunque las oportunidades de políticas sean respuestas al cambio de las mismas. La renovación de un programa de políticas, por ejemplo, crea una oportunidad para que muchos participantes intenten introducir su preocupación o proyecto favorito. En otras ocasiones, el proceso puede ser impredecible. Los emprendedores de políticas (policy entrepreneurs) deben estar preparados, su propuesta favorita en marcha, su problema particular bien documentado, si no la oportunidad desaparecerá. Se podría adelantar que el caso del Reino Unido se asemejaría al proceso por el cual se abren ventanas de oportunidad de forma predecible ya que la licencia para emitir entre la BBC y el Estado británico se renueva cada diez años.

Finalmente, surge en este trabajo una segunda hipótesis en relación al estudio del cambio en las políticas públicas de Estados miembros de la UE:

Hipótesis II: Los cambios, aunque las fuerzas de transformación fueran las mismas -Europa-, son contexto-dependientes.

Hay cambios que no son explicables considerando solo factores políticos internos en países miembros de la UE. Por otro lado, la introducción de la dimensión europea en el análisis de sus políticas públicas tiene resultados divergentes. Los actores y los niveles de gobierno que intervienen en el proceso de predecisión de la política son variados. Sus ideas, intereses y valores son distintos. Por ejemplo, en relación a la teoría de Sabatier (1998) del sistema de Coaliciones Promotoras (Advocay Coalitions) para la explicación del cambio en políticas públicas, nos recuerda que las mismas se desarrollaron originalmente teniendo en mente la experiencia norteamericana. ¿Cómo podría aplicarse el sistema de Coaliciones Promotoras a otros países, particularmente aquellos con culturas diferentes, sistemas parlamentarios, o a aquellos sin tradición democrática? (1998: 120). Para este estudio interesa la opinión del autor 32 (1998: 121) que dice que el sistema de Coaliciones Promotoras debería aplicarse al 
cada vez más complejo conjunto de relaciones que están surgiendo dentro de la UE, ya que sus instituciones -la Comisión Europea en particular, el Consejo de Ministros, y el Parlamento Europeo- están desplazando a las instituciones nacionales como la principal loci en la explicación del cambio de políticas públicas (Peterson 1995; Richardson 1996)". Sin embargo, el artículo entiende que este análisis, aunque útil para comprender el funcionamiento de la UE, deja de lado el estudio de los impactos que es el enfoque que aportamos. Quizás, al final del mismo párrafo, Sabatier introduce sin mencionarlo explícitamente el enfoque de europeización. Dice el autor que "las instituciones nacionales siguen siendo importantes en la implementación de las directivas de la UE como fuente de ideas de políticas de las propias directivas (Héritier, 1996)". Esta es una hipótesis difícil de validar en esta investigación. Sin embargo, quizás, las nociones en relación a los servicios públicos de televisión sean producto de la combinación del resultado del proceso iniciado en 1979 en el Reino Unido y su incorporación a la lógica de la UE, produciendo cambios en esa dirección en los demás países miembros como el caso español. Richard Lowi en el proceso de esta investigación mencionó que si se pudiera demostrar esto sería un best-seller ${ }^{17}$.

\section{ANÁLISIS DE LAS POLÍTICAS DE SERVICIO PÚBLICO EN EL REINO UNIDO: CAMBIOS SUTILES Y RADICALES DESDE 1979 A 2010}

A continuación se muestra el análisis de los procesos que han conformado las ideas y definición de problemas, así como de la formación de las agendas gubernamentales como determinantes del cambio en las políticas de servicio público de televisión británicas, teniendo en cuenta, además, el proceso de integración europea. Es un análisis del cambio de la BBC.

Como resumen de los cambios, se podría decir que hasta 1979 los orígenes históricos de la BBC desde su creación en 1926, se mantuvieron como fuerzas inflexibles al cambio: su independencia tanto de los poderes públicos como económicos, su autorregulación, su financiación estable a través del canon, su sistema de rendición de cuentas y transparencia ${ }^{18}$.

Sin embargo, la BBC del período estudiado se puede describir como continuista y, al mismo tiempo, de cambios profundos, aunque silenciosos respecto a sus orígenes y evolución desde 1926. La continuidad se consolidó en la renovación de la llamada Carta Real (Royal Charter) de 1996. Por otro lado, la BBC introdujo una nueva cultura de gestión orientada al mercado (Nueva Gestión Pública) ${ }^{19}$,

17 Entrevista realizada por el autor en el transcurso de la Oxford Media Convention de enero de 2004. Richard Lowi era el Director General de la Competencia de la Comisión Europea en el momento de la entrevista.

18 Para un análisis detallado, consultar, por ejemplo: Seymur-Ure, (1997); Negrine (1989); Curran y Seaton (1997); y Blumler (1992,1993). (2001).

19 Para una conceptualización de la Nueva Gestión Pública, consultar por ejemplo: Olías de Lima 
influenciado por las políticas (policy stream - Kingdon, 1995) que el gobierno conservador de Margaret Thatcher comenzó a introducir una vez que ganó el poder en 1979.

Por otro lado, la política de la BBC de los gobiernos laboristas de Tony Blair fue una continuación de los gobiernos conservadores precedentes en cuanto a su gestión y comercialización, concluyendo a partir del 2003 en un cambio radical con la creación de una nueva estructura regulatoria, de transparencia y de rendición de cuentas, y la cesión de competencias al nuevo superregulador de lo audiovisual y las telecomunicaciones Office for Communications en el año 2003, con la aprobación del 2003 Communications Act (Ofcom).

Por último, las nuevas tecnologías de la información y de la comunicación, así como los procesos de europeización ${ }^{20}$ han tenido también una influencia en el devenir de la BBC de los últimos 30 años.

\section{1) Orígenes de las ideas, definición del problema y formación de la agenda}

Es interesante describir de forma somera el proceso de origen y construcción de la $\mathrm{BBC}$ como institución de servicio público para comprender los principales cambios acontecidos en los últimos treinta años. Resultado de ese proceso se derivan las principales características que le han permitido ser reconocida como el servicio público de televisión paradigma de independencia.

La característica principal que le ha conferido a la BBC tal reconocimiento de independencia se encuentra en la creación de una institución como solución de políticas (policy solution), así como a su sistema de regulación desde 1926. De forma general, una corporación pública es un organismo público que opera a favor del interés general, regulado por el gobierno bajo normas que emanan del parlamento o poder legislativo. Una de las razones por las cuales se entendió que la BBC debería tomar la forma de corporación pública es que era un nuevo instrumento de gestión de los servicios públicos que, simplemente, se entendía útil en ese momento de la historia británica ${ }^{21}$. La preocupación fundamental era la gestión independiente tanto de los poderes económicos como políticos. En el caso concreto de la radiodifusión (la televisión no aparece hasta el período de entreguerras), la creación de un monopolio a través de una corporación pública se vio influenciada por un informe de la Post Office, organismo bajo cuya competencia estaba la radiodifusión. En él se tomó como ejem-

20 Aunque no ha sido el objetivo de este artículo indagar en procesos de globalización, se reconoce el proceso y es, sin duda, obligado abordarlo en futuras investigaciones como esencial en la elección de políticas públicas tanto de la UE como de sus Estados miembros.

21 Se pueden encontrar otros ejemplos en la misma época como The Port of London Authority (1908) o la Forestry Commission (1919). En 1920, era ya común la creación de corporaciones públicas como solución para la implementación de servicios públicos. 
plo el caso de la regulación de la radiodifusión en Estados Unidos bajo el gobierno de Hoover que supuso un absoluto caos consecuencia del nacimiento de numerosas compañías sin un control centralizado (Curran y Seaton, 1997: 115). Se creyó, entonces, que se necesitaba una solución cuya gestión demandara una nueva forma de administración.

Curran y Seaton (1997: 116) apuntan que el desarrollo de una corporación pública depende del rechazo tanto a las fuerzas del mercado como a los poderes políticos a favor de su control planificado y eficiente por expertos. Las ideas en forma de informes por parte de diferentes stakeholders (actores afectados por la política pública que intervienen o no en el proceso de toma de decisiones de la misma) fueron construyendo la corriente de políticas siguiendo un debate sereno y plural característico del sistema político británico.

Por otro lado, el liderazgo fue otra de las características de la definición y éxito como servicio público de la BBC. La determinación y compromiso personal de John Reith, su primer director general, impresionó al personal de la BBC, a la Post Office y al director de la asociación de productores ${ }^{22}$; incluso al Primer Ministro Baldwin. Reith creía que el sistema de competencia capitalista, aunque con sus ventajas, no era eficiente. Reith defendió que para que la radiodifusión fuera explotada en toda su dimensión debería estar gobernada por prioridades sociales, no financieras. Por otro lado, la $B B C$ se fundó en el rechazo a la interferencia política, aunque los políticos creían que la BBC estaba bajo su autoridad.

En relación al sistema de rendición de cuentas, un tema siempre discutido y mejorado desde entonces, los directores de la BBCompany se sustituyeron por "gobernadores" elegidos públicamente, y se convirtieron en los defensores del interés público. En cuanto a la relación entre la institución y el Estado, la BBC se basó en una autorregulación, independiente y con mecanismos de rendición de cuentas al ciudadano, no al Estado o al mercado, claros, aunque insuficientes. A cambio de una situación privilegiada frente al mercado, la $\mathrm{BBC}$ ha sido, y es, uno de los organismo públicos más y mejor regulados. Al mismo tiempo, cada uno de los Royal Charter (licencia para operar), así como su contrato para funcionar (Licence and Agreement - contrato detallado de derechos y obligaciones) desde 1926, renovado normalmente cada diez años, ha ido definiendo claramente sus obligaciones acorde a los tiempos. La gran autonomía de la corporación pública supuso algunos problemas en cuanto a los principios de las democracias liberales. Como apunta Etzioni-Halevy (1987: 7), las mismas se suponían controladas y no controladas al mismo tiempo por parte de los gobiernos.

22 Aunque no hay espacio para detallar su historia, recordemos que antes de constituirse como corporación pública, ya existía la British Broadcasting Company (BBCompany) desde 1922, compañía privada que controlaban los productores de aparatos de radio. 


\section{2) Principales resultados de la investigación}

Siguiendo la teoría de las corrientes múltiples de Kingdon, la corriente política se conformó con la entrada en el gobierno del partido conservador que lideraba Margaret Thatcher en 1979. El partido conservador había prometido que si resultaba ganador, se cortarían los gastos y los impuestos, se limitaría el poder del Estado y se eliminarían las restricciones y regulaciones en áreas de políticas como la financiera, la salud y vivienda. Estas políticas se vieron influenciadas por creencias de corte individualista, monetarista, contrarias al estado y las ideas igualitarias. El objetivo de la llamada New Right ${ }^{23}$, ya una vez en el gobierno, fue revitalizar la economía mediante la vuelta a una forma de capitalismo más agresiva. La política de servicio público de televisión, y la BBC en concreto, no fueron una excepción.

Pasó algún tiempo hasta que las ideas políticas de la New Right se aplicaran en su totalidad a la política de servicio público de televisión y a la política audiovisual en general: pruebas piloto para que la BBC liderara el desarrollo del servicio audiovisual digital (Home Office - Ministerio de Interior ${ }^{24}$, 1981); liberalización del mercado audiovisual liderado por el Ministerio de Industria y Comercio (DTI), lo cual afectó también a la BBC. La crisis económica hizo creer a miembros de los gobiernos de Thatcher, a principios de 1980, que una de las soluciones podría ser el desarrollo de la "sociedad de la información" (Negrine, 1985). Esto fue el resultado de entender que si el Reino Unido era lo suficientemente rápido, lideraría la "revolución de la información" en el mundo y, además, crearía millones de empleos (Hunt Report, 1982; White Paper on Cable, 1983; Cable and Broadcasting Act, 1984).

Estas iniciativas coincidieron en el tiempo con la creación del Comité Peacock (1986) para evaluar los efectos de la introducción de publicidad en los servicios nacionales de la $\mathrm{BBC}^{25}$ (1986: 1). Después de un proceso de debate y participación de los actores interesados en la política (BBC, gobierno, industria de la publicidad, etc.), y de alguna forma sorprendente, el Comité Peacock rechazó la introducción de publicidad en la BBC, y propuso varios aspectos que causaron controversia, como la de convertir a la $B B C$ en un servicio por subscripción; vender las emisoras de radio de la BBC; o incrementar la cuota de la BBC para la producción independiente a un $45 \%$ en diez años (en el año 1992 la cuota aumentó al 25\%). Esto se podría entender como una victoria del policy entrepreneur, en palabras de Kingdon, de los productores independientes. Sin embargo, en esta fase de los gobiernos conservadores los cambios fueron relativamente limitados y circunscritos a dinámicas internas.

23 New Right se refiere a las nuevas ideas económicas liberales que definieron el programa del partido conservador en las primeras elecciones de 1979. Para más información: Horton y Farham, 1999; Cockett, 1995; y Bosanquet, 1983.

24 El Ministerio de Interior (Home Office) fue durante esta etapa el organismo competente para el desarrollo de las políticas de servicio público de televisión.

25 El autor quiere agradecer la disponibilidad y amabilidad de Sir Alan Peacock en concederme varias entrevistas para la realización de este artículo, en un ejemplo más de la facilidad para investigar en el Reino Unido. 
Sin embargo, tras la victoria de 1987 el gobierno de Thatcher comenzó una reestructuración del sistema audiovisual a gran escala. En 1988 se publicó el White Paper del gobierno Broadcasting in the 1990s: Competition, Choice and Quality, donde comienzan a proponer cambios relevantes en la BBC y en todo el sector audiovisual privado: privatización de las horas nocturnas de uno de los canales de la BBC; introducción progresiva de servicios de televisión de la BBC con la idea de eliminar la financiación a través del canon; introducción de esponsorización responsable. La BBC mantendría constitucionalmente su estatus como corporación pública, autorregulada y financiada mediante el canon ${ }^{26}$. Poco a poco, sin embargo, los cambios iban transformando a BBC de forma incremental.

En 1992, el ministro de Patrimonio, Peter Brooke (el entonces competente de la BBC), publicó un Green Paper titulado The Future of the BBC(DNH, 1992). En noviembre de 1992, una semana más tarde, la BBC publicó su estrategia de futuro Extending Choice (BBC, 1992). Aunque no se aprecian grandes cambios, el gobierno tenía aún margen para cambiar la BBC a través de la presión que le permitía el sistema de financiación, ideas contenidas en el Peacock Committe (corriente de políticas). En 1985, el ministro de Interior responsable de la BBC, Leon Brittan, ejerció una presión inicial sobre la BBC disminuyendo el incremento de su canon. Además, en 1987, Douglas Hard, el sucesor de Brittan, indexó el canon a la inflación general -menor a la inflación del sector audiovisual- y comenzó esa indexación desde una base menor que había presupuestado la propia BBC (Goodwin, 1998).

En relación al sistema de rendición de cuentas de la $B B C$, esencial para la calidad de los sistemas políticos democráticos, el órgano de gobierno de la BBC, el Board of Governments, mantuvo sus competencias sobre las decisiones editoriales. Sin embargo, el gobierno utilizó su influencia en el nombramiento del presidente del Consejo de Gobernadores y Dirección General de la BBC: Marmaduke Hussey en octubre de 1986; en enero de 1987, Michael Checkland, un contable, fue nombrado Director General de la BBC, y John Birt subdirector. El resultado fue la introducción de una cultura de gestión que cambiaría profundamente el devenir de la BBC a través de los principios marcados por la Nueva Gestión Pública (eficiencia, economía y eficacia - las famosas $3 \mathrm{Es}^{27}$ ). Desde la entrada de los mencionados nombramientos, el término "eficiencia" a través de la reducción de costes y el aumento de las operaciones comerciales fueron los dos focos en los que se basó la estrategia financiera de la BBC (informe de Ian Phillips -enero de 1990; reducción de 2.000 puestos de trabajo, recursos y costes, a través de la racionalización de las actividades de la BBC, así como mejorar la productividad; iniciativa Producer Choice-creación de mercados internos en la BBC, abril de 1993).

26 En España no existe el canon, lo que es un caso excepcional en la UE.

27 La BBC comenzó un programa de formación a sus empleados de todas sus secciones en esta filosofía de gestión desde 1990. Para ello, contrató a uno de los centros universitarios más importantes en estudios de empresa y gestión, el Centre for Management Studies de la Universidad de Bradford. El autor tuvo la oportunidad de entrevistar en varias ocasiones a su directora, la profesora Judith Clifton. 
Otro de los cambios, en línea con la corriente de políticas de la New Right en el gobierno, fue la creación del servicio mundial de la BBC en 1995 (World Service Television - WSTV) como instrumento para convertir a la BBC en líder del sector de las comunicaciones a nivel global. Además, se privatizó, a través de la Ley Audiovisual de 1996 -Broadcasting Act (1996)- los puntos de transmisión de la BBC.

El 30 de abril de 1996 se aprobó el nuevo Royal Charter y el Licence and Agreement donde se confirmaron todos los cambios descritos: se reorganizó la estructura de la $B B C$ en seis departamentos (gestión, producción, recursos, noticias y actualidad, Servicio Mundial de Televisión -WSTV-, y el Centro Corporativo).

A los tradicionales principios del primer director general John Reith -información, formación y entretenimiento-, en este período se añadieron economía, eficiencia y eficacia.

En abril de 1997 ganó las elecciones el partido Laborista de Tony Blair. Su política sobre la BBC se puede calificar de continuista y, al mismo tiempo, de "radical". Continuista en cuanto a la profundización de las políticas de los gobiernos conservadores precedentes sobre todo en relación a los aspectos de gestión y comercialización; y "radical", porque es en el año 2003 que cambia, por primera vez en su historia, el sistema de regulación de la $\mathrm{BBC}$, pasando a ser regulada, en parte, por una institución independiente, la Office for Communications (Ofcom), creado a través de la Ley de las Comunicaciones (Communications Act) de 2003.

El primer cambio fue trasladar las competencias sobre la $\mathrm{BBC}$ a un nuevo ministerio, el Department for Culture Media and Sports (DCMS), nombrando a Chris Smith su primer responsable hasta el año 2001.

En 1997, el gobierno laborista ejerció el Royal Charter de 1996 firmando un acuerdo con la compañía privada Flextech para la creación de una joint-venture con el Servicio Mundial de Televisión (WSTV) de la BBC. En 1998, firmó un contrato de 340 millones de libras con la compañía Discovery Channel (Humphreys, 1999: 223); la BBC comenzó el servicio de noticias 24 horas (News 24); el BBC Online.

En relación al canon, en octubre de 1998 el ministro Smith creó un comité especial para buscar vías alternativas de financiación, aunque seguiría siendo la principal fuente de ingresos para la BBC en la renovación del nuevo Royal Charter de 2006. Tras las elecciones del 2001, Tessa Jowel fue nombrada ministra del Department for Culture, Media, and Sports. Enseguida aprobó la creación de nuevos canales digitales: $\mathrm{BBC} 4$ new arts, dos canales infantiles, y un canal juvenil, $\mathrm{BBC}$.

Quizás el cambio más importante fue la creación de Ofcom (2003 Communications Act) y la renovación del Royal Charter y el Licence and Agreement en 2006. En 38 la Cláusula 264 (3) se le confiere a Ofcom la revisión de las obligaciones de servicio 
público de televisión, incluyendo a la $\mathrm{BBC}$. Es un hecho insólito y novedoso del tradicional sistema de autorregulación de la corporación desde 1926.

Otro hecho relevante es la definición de servicio público a través de una Ley emanada del Parlamento (2003 Communications Act, Cláusula 264-4), técnica inédita en la historia de la $B B C$ que, como veremos más adelante, no se entendería sin la existencia de la UE y sus políticas.

El 1 de enero de 2006 entró en vigor el nuevo Royal Charter y el Licence and Agreement para los próximos diez años, hasta el 2016. Se reconoce la independencia editorial de la BBC. Sin embargo, esta vez, los cambios más relevantes fueron un nuevo diseño de organización y gestión sin precedentes en la historia de la BBC. Principalmente, se creó un órgano regulador dentro de la estructura organizativa de la BBC, el Consejo Ejecutivo (Executive Board), así como una regulación externa por parte de Ofcom. La BBC la gobierna el Ilamado Trust, que establece su dirección estratégica, sus prioridades, representa al interés de los ciudadanos que pagan el canon, y realiza un seguimiento general del trabajo del Consejo Ejecutivo. El Trust trabaja de forma regular con los Consejos de Audiencia (Audience Councils) -órganos de la BBC distribuidos por todo el territorio nacional- para conocer las necesidades y preocupaciones de la audiencia. Ambos, Trust y Executive Board, reemplazan al Consejo de Gobernadores.

Por lo tanto, el Trust es el cambio más relevante en términos de regulación, pero también en cuanto al sistema de transparencia y rendición de cuentas. La separación de la regulación de la gobernanza de la BBC y el establecimiento del Trust como órgano unitario se estableció para fortalecer aún más su sistema de rendición de cuentas. Uno de los aspectos más novedosos fue la creación del llamado Public Value Test (PVT) para evaluar las propuestas de la BBC de creación de nuevos servicios. La BBC no puede crear ningún servicio nuevo, o realizar cambios significativos en uno existente, sin el permiso del Trust. El PVT es una forma de evaluar el valor de lo público contra su impacto en el mercado (por ejemplo, si un nuevo servicio de radio produce un valor añadido a los ciudadanos, pero, sin embargo, daña los intereses comerciales de otras estaciones de radio existentes).

Por último, la introducción de la variable Unión Europea de acuerdo con el enfoque y metodología de europeización nos ayudará a completar el dibujo de las políticas de servicio público de televisión británico de los últimos treinta años. Quizás de esta forma obtengamos algunas claves que no hagan comprender mejor el proceso de integración europea.

Europeización ha jugado un papel en las políticas de servicio público de televisión del Reino Unido. La metodología utilizada en esta investigación ofrece un dibujo más completo de los análisis sobre el cambio de políticas públicas. Europeización, así como su diseño de investigación, completa la historia del servicio público de televisión en el Reino Unido. La introducción de la dimensión europea ha demostrado ser 
esencial para estos fines. Este nuevo enfoque ofrece también claves para entender el futuro cercano de los dos niveles europeo y nacional.

El proceso de europeización en el Reino Unido comienza, principalmente, en el periodo laborista (1997-2010) que siguió caminos diferentes en relación a Europa y en comparación con los gobiernos conservadores. Se mostró una estrategia paralela a la de la Comisión Europea en relación a las políticas de servicio público de televisión según se extrajo de las entrevistas realizadas en el Reino Unido y Bruselas. Sin embargo, no se han encontrado elementos que determinen una relación causal, aunque sí una coincidencia en el tiempo. El análisis muestra que los actores políticos participantes (stakeholders) en la políticas de servicio público de televisión británica han aprendido a explotar las oportunidades que se han presentado dentro de un proceso de elaboración de políticas caracterizado por estructuras de oportunidad múltiple (Richardson, 2001) como es el caso de la existencia de la UE. Este hallazgo es esencial para entender el proceso de elaboración de las políticas de los Estados miembros de la UE. Sin embargo, sería necesario realizar un análisis más detallado de este punto ya que podría darnos más claves sobre posibles procesos de europeización.

En relación al impacto de la dimensión europea, la UE no ha sido un reto importante para los responsables británicos de la elaboración de la política de servicio público de televisión hasta hace pocos años. En concreto, las presiones más relevantes para la BBC tienen su origen en la política de competencia de la UE. Esta ha tenido la capacidad de cuestionar tanto los objetivos que definen los servicios públicos de televisión, como los mecanismos por el que tales servicios se regulan y financian. El seguimiento de la UE ha aumentado por la influencia de los operadores comerciales que entienden que su viabilidad comercial y capacidad para desarrollar nuevos servicios se ve amenazada por las actividades de operadores públicos bien establecidos y, en su opinión, con un sistema financiero privilegiado. Los principales impactos causados por procesos de europeización han sido los siguientes: definición del servicio público a través de un acto legislativo formal (La ley de Comunicaciones del 2003); el conflicto de la BBC 24 News; y el nuevo sistema de regulación (Office for Communications - Ofcom y el BBC Trust). Finalmente, el conjunto de comunicaciones de la Comisión Europea del año $2002^{28}$ ha seguido un proceso paralelo a las reformas del caso

28 La Directiva marco forma parte del "paquete sobre telecomunicaciones" ideado para refundir el marco regulador de las telecomunicaciones con vistas a hacer más competitivo el sector de las comunicaciones electrónicas. Este nuevo marco regulador está integrado por esta Directiva y por otras cuatro directivas específicas, a saber:

- la Directiva relativa a la autorización de redes y servicios de comunicaciones electrónicas (Directiva de autorización);

- la Directiva relativa al acceso a las redes de comunicaciones electrónicas y recursos asociados, y a su interconexión (Directiva de acceso);

- la Directiva relativa al servicio universal (Directiva de servicio universal);

- la Directiva relativa al tratamiento de los datos personales (Directiva de intimidad y comunicaciones electrónicas).

A esta lista hay que añadir la Decisión relativa a un marco regulador de la política del espectro radioeléctrico (Decisión del espectro radioeléctrico). En diciembre de 2009 se modificó el "Paquete telecomuni- 
británico. Además, en relación a la regulación de los contenidos audiovisuales, que también afectan a la programación de la BBC, la política de la UE más relevante se refleja en la Directiva de Servicio de Comunicación Audiovisual (2010/13/UE) que modificó y actualizó la Directiva 89/552/CEE del Consejo, de 3 de octubre de 1989, sobre la coordinación de determinadas disposiciones legales, reglamentarias y administrativas de los Estados miembros relativas al ejercicio de actividades de radiodifusión televisiva.

La Comisión Europea ha tenido un papel determinante en relación a la definición de la política pública y de sus estructuras regulatorias. Esto podría entenderse como un proceso de europeización caracterizado por una presión de la UE y su paradigma de políticas de competencia en relación a los servicios públicos. ¿Cómo podemos medir ese impacto de la UE? El artículo entiende que impactos de este tipo son difíciles de medir en términos cuantitativos. Sin embargo, el esfuerzo realizado por la BBC y los responsables de la política en el Reino Unido podría ser un ejemplo sobre cómo medir el valor público de la gestión y del sistema de rendición de cuentas de la BBC (especialmente el Public Value Test que desde el año 2004 sirve para realizar un análisis de impacto en el mercado de la propuesta de creación de nuevos servicios ofrecidos por la $\mathrm{BBC}$ ). Estos criterios podrían darnos indicadores medibles para comprender de forma más detallada el impacto de la UE en los servicios públicos de televisión nacionales. Claramente, la introducción de mecanismos de valoración de creación o cambio de servicios públicos por parte de la BBC es una idea típica de lo público donde el mercado y el proceso de integración europea son actores relevantes.

Los marcos de políticas utilizados por los policy-makers británicos han convergido con los de las políticas de competencia de la propia UE en relación a la política de servicio público de televisión. No se ha encontrado evidencia empírica sobre si esta convergencia es resultado de procesos de up-loading, del poder coercitivo de las ideas, o, simplemente, una coincidencia en tiempo e ideas para la elección de la mejor opción de políticas dentro de un escenario global de difusión de nuevas tecnologías de la comunicación. Sin embargo, según sugiere Richard Lowi ${ }^{29}$, el proceso de europeización ha podido ser el resultado de mecanismos de presión en relación a la definición del servicio público de televisión, y a una combinación de procesos de transferencia de políticas, lesson drawing y up-loading desde el Reino Unido a la Comisión Europea en cuanto a la definición, de la política, y alternativas (policy options) sobre los nuevos servicios (New services). Sin embargo, la confluencia de ideas sobre servicio público de televisión entre Reino Unido y Comisión Europea no ha producido cambios, ya que existe un proceso de "encaje" o "fit" en términos de Börzel (2005).

En cualquier caso, la UE influye en las políticas del Reino Unido en forma de impactos. Si la solución de políticas se basa en las mismas ideas que el Estado miembro, 
el impacto será positivo, como ha sido el caso del Reino Unido (adaptation tracking). Esto ha creado una convergencia entre las tradiciones institucionales y regulatorias británicas y las normas europeas.

En la investigación han aparecido varias cuestiones: ¿Se podría describir como un proceso de europeización una política originada en el Reino Unido y transferida a la UE, “britanizando" la Comisión Europea en el área de políticas de servicio público de televisión que ha cambiado éstas desde 1979? (ayudas de Estado, transparencia y separación de cuentas, un único regulador, etc.). Estos cambios se produjeron muchos años antes de que la Comisión los adoptara como su propia política. ¿Existe alguna connivencia entre la Comisión Europea y el Reino Unido? ¿Existe un proceso de "uploading" o, simplemente, un proceso paralelo basado en las mismas ideas y estructuras sobre el servicio público de televisión? Estas cuestiones no han sido resueltas en esta investigación.

Como hemos visto en secciones anteriores, existe un cambio de paradigma de servicio público de televisión que de forma incremental se introdujo en el Reino Unido a partir de la confluencia de problemas, política y políticas desde 1979; y de forma radical desde que comenzó a gobernar el Nuevo Laborismo en 1997, que ha terminado con la histórica autorregulación de la BBC. Algunos aspectos de la $\mathrm{BBC}$ los regulan organismos externos. Cuando se trata de política de competencia, la BBC la regula la Office of Fair Trade (OFT), la Comisión Europea, y Ofcom. Ofcom regula también otros aspectos de la BBC, como por ejemplo el Ofcom's Fairness Code. El futuro de Ofcom como regulador de la BBC se está convirtiendo en el enlace principal entre la Comisión Europea y el Reino Unido. A pesar de que Ofcom tiene carácter consultivo en relación a la $\mathrm{BBC}$, los asuntos sobre servicio público bajo su competencia son una consecuencia de los requerimientos de la Comisión Europea: “una definición precisa de servicio público audiovisual; la asignación formal de servicio público a uno o más operadores, queden ser supervisados por un organismo o autoridad de los Estados Miembros; y que la financiación pública sea proporcional al grado de cumplimiento de la misión de servicio público". Ofcom es un organismo independiente que realiza una revisión y seguimiento de las obligaciones de servicio público de los operadores de televisión en el Reino Unido: BBC, ITV, Channel 4, SC4 y Five).

El proceso descrito anteriormente es parte también del cumplimiento de la Directiva de la Comisión Europea 2000/52/EC sobre transparencia y separación de cuentas. La Directiva efectivamente requiere un doble mecanismo de transparencia para los Estados miembros: primero, transparencia sobre las relaciones financieras entre las autoridades públicas y los operadores del servicio; y, en segundo lugar, con la Comisión. Provee de información financiera sobre los Estados miembros que puede ser requerida por la Comisión, mientras que otra información se provee en forma de informes anuales.

En relación a la licence fee o canon de la BBC, uno de sus principales activos his42 tóricos para financiar su servicio público, la Comisión Europea ha publicado un borra- 
dor de Comunicación estableciendo las bases para las ayudas del Estado a los servicios públicos de televisión. Los Estados miembros tuvieron la oportunidad de emitir sus opiniones sobre el texto propuesto. Los comentarios se enviaron el 15 de enero del año 2009. Los temas clave para discusión incluyeron más flexibilidad para los operadores públicos a fin de cumplir con los retos del nuevo escenario de medios de comunicación, los principios relacionados con la definición de servicio público y la supervisión de las actividades de servicio público a nivel nacional. Sobre la base de esos comentarios, la CE adoptó una nueva Comunicación (State aid action plan - Less and better targeted state aid: a roadmap for state aid reform, 2005-2009) en la primera mitad del año 2009.

En una nueva "batalla" sobre definición de los servicios públicos de televisión y los procesos de europeización, Neelie Kroes, la Comisaria de la CE responsable de la política de competencia, dijo ya en 2005 que "la Comisión Europea está dispuesta a diseñar reglas más estrictas que permitan a los canales audiovisuales nacionales competir mejor con los nuevos medios de comunicación, definir las obligaciones de servicio público y mejorar la supervisión nacional de sus actividades. Pero los que se oponen a estas propuestas dicen que perjudicaría a los servicios públicos audiovisuales en la explotación de nuevas tecnologías de medios de comunicación" (Kroes, 2005) Dijo, además, que quería que "el sector audiovisual alcance los retos del nuevo escenario de medios, permitiendo un servicio público moderno y de alta calidad, y al mismo tiempo manteniendo el juego limpio entre diferentes actores". Los Estados tienen un amplio margen para definir qué es exactamente servicio público de televisión, mientras mantenga una competencia leal. Las propuestas permitirían a los operadores conseguir más financiación para afrontar los futuros cambios y los costes.

El gran impacto de la política de competencia de la UE se demuestra en el resultado de los tres siguientes asuntos llevados a cabo por la Comisión Europea ${ }^{30}$ : el asunto "BBC News 24" (1999); el asunto "new digital-only TV and radio channels" (2002); y, el asunto “BBC Digital Curriculum” (2003). Sin embargo, en ninguno de estos casos se encontró ayudas del Estado británico a la BBC, incompatibles con el Tratado31.

Los procesos de europeización han demostrado tener un impacto en la BBC, el operador de servicio público más independiente y autorregulado del mundo. Los conceptos de "fit" (encaje) y "misfit" (no encaje) sirven para explicar las relaciones entre la UE y la BBC. En el futuro próximo, europeización aparecerá relacionada con las ayudas del Estado en relación a:

(a) Servicios inapropiados. La BBC no debe utilizar fondos del Estado para ofrecer servicios que no le haya concedido el Estado previamente.

30 Casos N 88/98, N 631/2001 y N 37/2003.

31 <http://www.reckon.co.uk/open/BBC_digital-only_channels>. Página consultada el 9 de diciembre de 2009 . 
(b) Gasto innecesario. La BBC no debe utilizar, o recibir, más financiación del Estado que la que necesite para ofrecer un conjunto de servicios concreto.

\section{CONCLUSIONES}

En primer lugar, el caso del Reino Unido muestra cómo el cambio en la etapa de construcción de la agenda y, por tanto, en la atención política, ha afectado a las políticas públicas a través del seguimiento de las ideas dentro de los procesos de definición de problemas de las políticas de servicio público de televisión. El estudio de las tres corrientes de Kingdon - problem, politics y policy- nos ha ayudado a comprender los principales cambios de la BBC. El artículo considera muy relevante el estudio de las ideas, el reconocimiento de los problemas y su definición; el proceso de elaboración de las políticas de servicio público de televisión; y el papel de los procesos políticos. Por otro lado, la evolución de tecnología de la televisión ha sido, es, y será un factor importante para comprender la formación de la agenda del caso del Reino Unido, como presión externa para el cambio en las políticas de servicio público de televisión.

Kingdon ha demostrado ser útil para identificar aquellas ideas que forman parte del proceso de definición de problemas y opciones de políticas públicas. Es en este punto donde la investigación muestra una innovación, mediante la introducción de un nuevo participante -La UE- dentro de los procesos de definición de problemas y construcción de la agenda doméstica o nacional. Así, esta investigación se ha basado en estas ideas para explicar el desarrollo de las políticas de servicio público de televisión en línea con Kingdon, ofreciendo una relación analítica con los procesos de europeización.

Los resultados han mostrado que la política de servicio público de televisión británica ha cambiado de forma incremental desde 1979 en línea con su propio paradigma de servicio público. Las ideas de este nuevo paradigma se introdujeron en los gobiernos del Reino Unido tras la ventana de oportunidad abierta en 1979.

En línea con la tradición de la BBC como institución pública, la Carta Real y el Acuerdo del año 2007 (Charter and Agreement) concedió a la BBC un espacio significativo para interpretar y ofrecer servicios públicos de televisión. Sin embargo, para comprender el futuro de la BBC, será necesario analizar los procesos de europeización por negociación, presión y coerción.

A nivel de la UE, aún se van a producir más cambios en cuanto a ayudas de Estado en un ejemplo de proceso sin retorno para la BBC. Después de la Sentencia Altmark ${ }^{32}$, la Dirección General de la Competencia (Unidad de Servicios de Interés General) ha adoptado un texto sobre la financiación de los servicios de interés económico

32 Altmark, caso C-280/00, sentencia de julio de 2003. 
general. Este podría ser el nuevo marco para presionar a la BBC y sus nuevos servicios.

Para finalizar, es obligado decir que sería necesaria una mayor evidencia empírica para poder validar teorías sobre la etapa de predecisión de las políticas públicas definición de problemas y formación de agendas- de Estados miembros de la UE, teniendo en cuenta la relación entre el proceso de integración europea y la elaboración de las políticas públicas nacionales de la forma que propone el diseño de investigación de europeización.

Por otro lado, hoy, las ideas viajan globalmente favorecidas por las nuevas tecnologías de la información y de la comunicación. Esto significa que las nociones de servicio público están influenciadas por lo que Manuel Castells llama el "Estado en red”. Esto significa que las relaciones de poder no se definen originalmente en las fronteras establecidas por los Estados (2009: 18). Y esto es relevante porque lo que se valora y se institucionaliza lo definen las relaciones de poder (Castells, 2009: 10). Es más, esas relaciones de poder contienen ideas. Probablemente, es importante considerar que para comprender las nociones de servicio público y su cambio en un escenario europeo de poder, las instituciones de la UE podrían actuar como filtros y proveedores tanto de procesos de europeización como de globalización. Por lo tanto, las ideas y los procesos de globalización deben tenerse en cuenta para futuras investigaciones.

La investigación se ha centrado en la etapa de predecisión de la elaboración de las políticas públicas para poder identificar los cambios e influencias de los procesos de europeización en los componentes de la superficie del sistema de servicio público de televisión británico. Sería interesante hacer un seguimiento de cómo esos cambios e impactos europeos que tienen lugar en la superficie afectan al proceso de implementación de la política en el futuro.

\section{REFERENCIAS BIBLIOGRÁFICAS Y DOCUMENTALES}

Albæk, E., Green-Pedersen, C. y Nielsen, L.B. (2004), “Making tobacco consumption a political issue in the United States and Denmark: The dynamics of issue expansion in comparative perspective", Journal of Comparative Policy Analysis, 9(1): 1-20.

Alberts, D.S. y Papp, D.S. (1997), The Information Age: An Anthology on Its Impact and Consequences. Washington: CCRP Publication Series.

Bachrach, P., y Baratz M.S. (1962), "Two Faces of Power”, The American Political Science Review, 56(4): 947-952.

Barzelay, M. y Gallego, R. (2006), “From New Institutionalism to Institutional Processualism: Advancing Knowledge about Public Management Policy Change”, Governance, 19(4): 531-557. 
Baumgartner, F.R., Green-Pedersen, C. y Jones, B.D. (1994), “Attention, Boundary Effects, and Large-Scale Policy Change in Air Transportation Policy, en D.A. Rochefort y R.W. Cobb, eds., The Politics of Problem Definition: shaping the policy agenda. Lawrence: University Press of Kansas.

Baumgartner, F.R., Green-Pedersen, C. y Jones, B.D. (2006), Comparative Studies of Policy Agendas. Londres: Routledge.

Baumgartner, F.R. y Jones, B.D. (1993), Agendas and Instability in American Politics. Chicago: University of Chicago Press.

British Broadcasting Corporation - BBC (1992), Extending Choice: The BBC's role in the New Broadcasting Age. Londres: BBC.

Broadcasting Act (1990), Londres: Stationary Office.

Broadcasting Act (1996), Londres: Stationary Office.

Blumler, J. (1993), "The British Approach to Public Service Broadcasting: from confidence to uncertainty", en R.K. Avery, ed., Public Service Broadcasting in a Multichannel Environment. Nueva York/Londres: Longman.

Blumler, J. (1992), Television and the public interest: vulnerable values in West European Broadcasting. Londres: Sage.

Blyth, M. (2002), Great Transformations: Economic Ideas and Institucional Change in the Twentieth Century. Cambridge: Cambridge University Press.

Bosanquet, N., (1983), After the New Right. Londres: Heinemann.

Bosanquet, N. (1981), "Sir Keith's reading list", Political Quarterly, 52: 324-341.

Börzel, T.A. (2005), "How the European Union interacts with its Member States", en C. Lequesne, ed., Member States and the European Union. Oxford: Oxford University Press.

Börzel, T.A. (1999), "Towards Convergence in Europe? Institutional Adaptation to Europeanization in Germany and Spain”, Journal of Common Market Studies, 37(4): 573-596.

Buller, J. y Gamble, A. (2002), “Conceptualising Europeanisation”, Public Policy and Administration, 17(2): 4-24.

Bulmer, S. (2009), "Politics in Time meets the Politics of Time: Historical Institutionalism and the EU Timescape", Journal of European Public Policy, 16(2): 307-324.

Bulmer, S. y Radaelli, C.M. (2005), "The Europeanisation of public policy?", en C. Lequesne y S. Bulmer, eds., (2005), The Member States of the European Union. Oxford: Oxford University Press.

Capano. G. (2003), “Administrative traditions and policy change: when policy paradigms matter. The case of Italian administrative reform during the 1990 s", Public Administration, 81(4): 781-801.

Capano, G. (1999), "Replacing the policy paradigm: higher education reforms in Italy and the United Kingdom 1979-1997. An historical-institutionalist analysis”, en D. Braun y A. Bush, eds., The power of ideas: policy ideas and policy change. Londres: Edward Elgar.

Castells, M. (2009), Communication power. Oxford: Oxford University Press.

CEC (Commission of the European Communities) (1980), "Commission Directive $4680 / 723 / E E C$ on the transparency of financial relations between Member States 
and public undertakings", Official Journal of the European Communities. L 195, 29:35-37.

CEC (Commission of the European Communities) (2000), Commission Communication on the Services of General Interest in Europe. COM (2000) 590 final.

CEC (Commission of the European Communities) (2000), "Commission Directive 2000/52/EC amending Directive 80/723/EEC (1980) on the transparency of financial relations between Member States and public undertakings", Official Journal of the European Communities. L 193: 0075-0078.

CEC (Commission of the European Communities) (2001), Communication Commission on the application of state aid rules to public service broadcasting. C 320 .

CEC (Commission of the European Communities) (2005), State aid action plan - Less and better targeted state aid: a roadmap for state aid reform 2005-2009 (Consultation document) $\{\mathrm{SEC}(2005) 795\}$. (COM/2005/0107 final).

Cobb, R.W. y Elder, C.D. (1975), Participation in American Politics. The Dynamics of Agenda-Building. Baltimore: The John Hopkins Press.

Cockett, R. (1995), Thinking the Unthinkable: Think-Tanks and the Economic CounterRevolution. 1931-1983. Londres: HarperCollins Publishers.

Corbett, A. (2005), Universities and the Europe of Knowledge. Nueva York: Palgrave Macmillan.

Communications Act (2003). Londres: Stationary Office.

Curran, J. y Seaton, J. (1997), Power without reponsibility: the press and broadcasting in Britain. Londres: Routledge.

March, J. G., y Olsen, J. P. (1972). "A garbage can model of organizational choice”, Administrative Science Quarterly, 17(1): 1-25.

Considine M. (1998), “Agenda setting in a parliamentary system”, Governance, 11: 297317.

Coughlin, J. (1994), "The Tragedy of the Concrete Commons: Defining Traffic Congestion as a Public Problem", en D.A. Rochefort y R.W. Cobb, eds., The Politics of Problem Definition: shaping the policy agenda. Lawrence: University Press of Kansas.

Dahl, R. (1989), Democracy and its critics. New Haven: Yale University Press.

Dahlgren, P. (2001), Television and the public sphere: citizenship, democracy and the media. Londres: Sage.

DCMS (1994), The Future of the BBC, Serving the Nation Competing world-wide. Londres: HSMO.

DCMS (1998), Television Licence Fee Will Rise According to Five Year Formula. Londres: Stationery Office.

DCMS, Press Release 310/98, Londres: Stationary Office, 15 de diciembre de 1998.

Deloitte (2009), The Deloitte State of Media Democracy survey. Londres: Deloitte.

Dimitrakopoulos, G. (2001), "Incrementalism and Path Dependence: European Integration And Institutional Change in National Parliaments", Journal of Common Market Studies, 39(I).3: 405-422.

Department of National Heritage - DNH (1992), The Future of the BBC: A consultation Document, Londres: HSMO. 
Department of National Heritage - DNH (1994), The future of the BBC: serving the nation, competing-worldwide. Londres: HSMO.

Dery, D. (2000), “Agenda setting and problem definition”, Policy Studies, 21(1): 37-47. Dolowitz, D. y Marsh, D. (2000), "Learning from abroad: the role of policy transfer in contemporary policy making”, Governance, 13(1): 5 - 23.

DTI/DCMS, A New Future for Communications, White Paper. Londres: Stationery Office, 12 de diciembre del 2000.

Dür, A. y Mateo González, G. (2004), «¿Más hombres ciegos y más elefantes? Una revisión de la literatura más reciente sobre la integración europea». Working Paper, 233. Barcelona: Institut de Ciències Polítiques i Socials. En línea: <http://ddd. uab.cat/pub/worpap/2004/hdl_2072_1224/ICPS233.pdf> (consulta: 2 de febrero de 2005).

Dyson, K. (1980), The state tradition in Western Europe. Oxford: Martin Robertson.

EC (Comunidades Europeas) (1997), Treaty of Amsterdam.

EC (Comunidades Europeas), Diario Oficial C 320, 15 de noviembre de 2001.

European Court of Justice, Altmark, case C-280/00, julio de 2003.

Etzioni-Halevy, E. (1985), Bureaucracy and Democracy. A political dilemma. Londres: Routledge/Kegan Paul.

Farnham, D. y Horton, S. (1996), Managing People in the New Public Services. Londres: Macmillan.

Featherstone, K. y Radaelli, C.M., eds. (2003), The Politics of Europeanisation. Oxford: Oxford University Press.

Flathaman, R.E. (1966), The public interest: an essay concerning the normative discourse of politics. Londres: John Wiley.

Foster, R., Egan J. y Simon J. (2004), “Measuring Public Service Broadcasting”, en D. Tambini y J. Cowling, eds., From Public Service Broadcasting to Public Service Communiactions. Londres: IPPR.

Gersick, C.J.G. (1991), "Revolutionary Change Theories: A Multilevel Exploration of the Punctuated Equilibrium Paradigm", The Academy of Management Review, 16(1): 10-36.

Green Cowles, M. y Risse, T. (2001), “Transforming Europe: Conclusions”, en M. Green Cowles, J. Caporase y T. Risse, eds., Transforming Europe - Europeanization and Domestic Change. Ithaca: Cornell University Press.

Green-Pedersen, C. (2007), "The Conflicts of Conflicts in Comparative Perspective. Euthanasia as a political issue in Denmark, Belgium and the Netherlands". Comparative Politics, 39(3): 273-291.

Greener, I. (2005), "The potential of path dependence in political studies", Politics 25(1): 62-72.

Goetz, K. y Hix, S. (2001), Europeanised Politics? European Integration and National Political Systems. Londres: Frank Cass.

Goodwin, P. (1998), Television under the Tories: broadcasting Policy 1979-1997. Londres: British Film Institute (BFI).

$48 \quad$ Polity Press. 
Hall, P. (1993), “Policy Paradigms, social learning, and the state”, Comparative Politics, 25(3): 275-296.

Hall, P. (1989), The Political Power of Economic Ideas: Keynesianism Across Nations. New Jersey: Princeton University Press.

Hall, P. (1986), Governing the Economy: the Politics of State Intervention in Britain and France. Cambridge: Polity Press.

Hall, S., "New Labour has picked up where Thatcherism left off', en The Guardian, 6 de agosto de 2003.

Héritier A., Kerwer, D., Knill, C., Lehmkuhl, D., Teutsch, M. y Douillet, A.C. (2001), Differential Europe: The European Union Impact on National Policy-making. Oxford: Rowan.

Baldwin, R. y Cave, M. (1999), Understanding Regulation: Theory, Strategy, and Practice. Oxford: Oxford University Press.

Hirst, P. y Thomson, G. (1996), Globalisation in question. Cambridge: Polity Press.

Haas, P.M. (1992), "Epistemic communities and international policy coordination". International Organization, 46(1): 1-35.

Hood, C. (1999), Regulation Inside Government: Waste-Watchers, Quality Police, and Sleaze-Busters. Oxford: Oxford University Press.

Hood, C. (1994), Explaining Economic Policy reversals. Buckingham: Open University Press.

Hood, C. (1991), “A public management for all seasons”, Public Administration, 69(1): 3-19.

Humphreys, P. (2000), "New Labour Policies for the Media and the Arts", en D. Coates y P. Lawler, eds., New Labour in Power. Manchester: Manchester University Press.

Humphreys, P. (1996), Mass Media and Media Policy in Western Europe. Manchester: Manchester University Press.

Irondelle, B. (2003), "Europeanization without the European Union? French military reforms 1991-96", Journal of European Public Policy, 10(2): 208-226.

Jenson, J. (1989), "Paradigms and the political discourse: protective legislation in France and the United States before 1914", Canadian Journal of Political Science, XXII(2): 235-256.

Jordan, B., Strath, B. y Triandafyllidou, A. (2003), "From Guardians to Managers: Immigration Policy Implementation in Europe", Journal of Ethnic and Migration Studies, 29(2): 195-224.

Jordana J. y Levi-Faur, D. (2004), The politics of regulation: institutions and regulatory reforms for the age of governance. Londres: Edward Elgar.

Kingdon, J.W. (1995), Agendas, Alternatives, and Public Policies. Boston: HarperCollins College Publishers.

Kroes, N. (2005), "EC state aid control: the case for reform”, GCR, 8(6): 37-38.

Kuhn, T. (1970), La estructura de las revoluciones científicas. México D.F.: Fondo de Cultura Económica.

Majone, G. (2001), “Políticas Públicas y Administración: Ideas, Intereses e Instituciones”, en M. Goodin y H.D. Klingemann, eds., Nuevo Manual de Ciencia Política. Tomo II. Madrid: Ediciones Istmo. 
March, J.G. y Olsen, J.P. (1989), Rediscovering Institutions: the organizational basis of politics. Nueva York: The Free Press.

Maynar Hutchins, R. (1947), The Commission on Freedom of the Press. Chicago: The University of Chicago Press.

McCombs, M. y Shaw, D. (1972), “The agenda-setting function of mass media”, Public Opinion Quarterly, 36: 176-187.

Meijerink, S. (2005), “Understanding policy stability and change. The interplay of advocacy coalitions and epistemic communities, windows of opportunity, and Dutch coastal flooding policy 1945-2003", Journal of European Public Policy, 12(6): 1060-1077.

Mucciaroni, G. (1994), “Problem Definition and Special Interest Politics in Tax Policy and Agriculture", en Rochefort, D.A. y Cobb R.W. (1994), The Politics of Problem Definition: shaping the policy agenda. Lawrence: University Press of Kansas.

Muñoz Saldaña, M. (2007), “Las exigencias básicas de la regulación comunitaria respecto de la configuración jurídica de las televisiones públicas europeas”, en A. Azurmendi, La reforma de la televisión pública española. Valencia: Tirant lo Blanch.

Negrine, R. (1985), Cable television and the future of broadcasting. Kent: Croom Helm Ltd.

Olsen, J. (1996), “Europeanization and Nation-State Dynamics”, en S. Gustavsson y L. Lewin, eds., The Future of the Nation State. Londres: Routledge.

Peacock, A. (1986), Report of the Committee on Financing the BBC. Londres: HSMO.

Pierson, P. (2004), Politics in Time. Princeton: Princeton University Press.

Pierson, P. (2000), "Increasing returns, path dependence, and the study of politics", American Political Science Review, 94(2): 251-274.

Pierson, P. (1996), "The Path to European Integration”, Comparative Political Studies, 29(2): 123-163.

Pierson, P. y Skocpol, T. (2002), “Historical Institutionalism in Contemporary Political Science”, en I. Katznelson y H.V. Milner, eds., Political Science: State of the Discipline. Nueva York: W.W. Norton.

Peters, B.G. (2001), “Agenda-Setting in the European Union”, en J. Richardson, ed., European Union, Power and Policy Making. Londres: Routledge.

Peters, B.G. (1994), "Agenda-Setting in the European community”, Journal of European Public Policy, 1(1): 9-26.

Pollack, M. (1997), “Delegation, agency, and agenda-setting in the European Community", International Organization, 51(1): 99-134.

Princen, S. (2007), “Agenda-setting in the European Union: a theoretical exploration and agenda for research", Journal of European Public Policy, 14(1): 21-38(18).

Princen, S. y Rhinard, M. (2006), "Crashing and creeping: agenda-setting dynamics in the European Union”, Journal of European Public Policy 13(7): 1119-1132.

Radaelli, C.M. (2008), 'Europeanization, Policy Learning, and New Modes of Governance', Journal of Comparative Policy Analysis, 10(3): 239-254.

50 Radaelli, C.M. (2005), “Europeanization: Solution or Problem”, en M. Cine
ne, eds., The Palgrave Guide to European Studies. Londres: Palgrave. 
Radaelli, C.M. (2003), “The Europeanization of Public Policy”, en K. Featherstone y C.M. Radaelli, eds., The Politics of Europeanisation. Oxford: Oxford University Press.

Radaelli C.M. (2002), "The domestic impact of European Union public policy: notes on concepts, methods, and the challenge of empirical research", Politique européenne, 5: 105-136.

Radaelli, C.M. y Saurugger, S. (2008), "The Europeanization of Public Policy in Comparative Perspective", Journal of Comparative Policy Analysis, edición especial, 10(3).

Rein, M. y Schön, D. (1994), Frame Reflection. Toward the Resolution of Intractable Policy Controversies. Nueva York: Basic Books.

Rhodes, R.A.W. (1994), "The hollowing out of the State: The changing nature of the public service in Britain", Political Quarterly, 65(2): 138-151.

Richardson, J., ed., (2001), European Union: Power and Policy-making. Londres: Routledge.

Richardson, J. (2000), "Government, Interest Groups and Policy Change", Political Studies, 48: 1006 - 1025.

Rochefort, D.A. y Cobb R.W. (1994), The Politics of Problem Definition: shaping the policy agenda. Lawrence: University Press of Kansas.

Rochefort, D.A. y Cobb, R.W. (1994a), "Instrumental versus Expressive Definitions of AIDS Policymaking”, en D.A. Rochefort y R.W. Cobb, The Politics of Problem Definition: shaping the policy agenda. Lawrence: University Press of Kansas.

Sabatier, P.A. (2007), Theories of the policy process. Londres: Westview Press.

Sabatier, P.A. (1999), "The advocacy coalition framework: an assessment”, en P.A. Sabatier, Theories of the policy process. Boulder: Westview Press.

Sabatier, P.A. (1998), "The advocacy coalition framework: revisions and relevance for Europe", Journal of European Public Policy, 5(1): 98-130.

Sabatier, P.A. y Jenkins-Smith H.C., eds., (1993), Policy change and learning. An advocacy coalition approach. Boulder: Westview Press.

Sartori, G. (2008), Homo videns. La sociedad teledirigida. Madrid: Taurus.

Schattschneider, E.E. (1960), The Semisovereign People: A Realist's View of Democracy in America. Nueva York: Holt, Rinehart, and Winston.

Seymur-Ure, C. (1997), The British Press and Broadcasting since 1945. Oxford: Blackwell Publishers.

Soroka, S. (2007), “Agenda-setting and Issue Definition”, en M. Orsini y M. Smith, Reconfiguring Policy Analysis: Contemporary Canadian Approaches. Columbia: University of British Columbia Press.

Stone, D.A. (1989), "Casual stories and the formation of policy agendas", Political Science Quarterly, 104: 281-300.

SustainAbility (2002), Good News and Bad - The Media, Corporate Social Responsibility and Sustainable Development. En línea <http://www.sustainability.com/library/ good-news-bad> (consulta: 2 de marzo de 2003).

Tallberg, J. (2003), "The agenda-shaping powers of the EU Council Presidency", Journal of European Public Policy, 10(1): 1-19. 
True, J., Jones, L., Bryan, D. y Baumgartner, F.R. (1999), “Punctuated-Equilibrium Theory Explaining Stability and Change in Public Policymaking”, en P.A. Sabatier, ed., Theories of the policy process. Londres: Westview Press.

Weiss, J.A. (1989), "The powers of problem definition: the case of government paperwork”, Policy Sciences, 22: 97-121.

Zahariadis, N. (2007), “The Multiple Streams Framework: Structure, Limitations, Prospects", en P.A. Sabatier, Theories of the Policy Process. Boulder: Westview Press.

Recibido: 1 de febrero de 2011

Aceptado: 23 de mayo de 2011 